\title{
A toolbox of molecular photoswitches to modulate the CXCR3 chemokine receptor with light
}

\author{
Xavier Gómez-Santacana ${ }^{1,2}$, Sabrina M. de Munnik ${ }^{1}$, Tamara A. M. Mocking ${ }^{1}$, \\ Niels J. Hauwert ${ }^{1}$, Shanliang Sun ${ }^{1}$, Prashanna Vijayachandran ${ }^{1}$, Iwan J. P. de Esch ${ }^{1}$, \\ Henry F. Vischer ${ }^{1}$, Maikel Wijtmans ${ }^{* 1}$ and Rob Leurs ${ }^{* 1}$
}

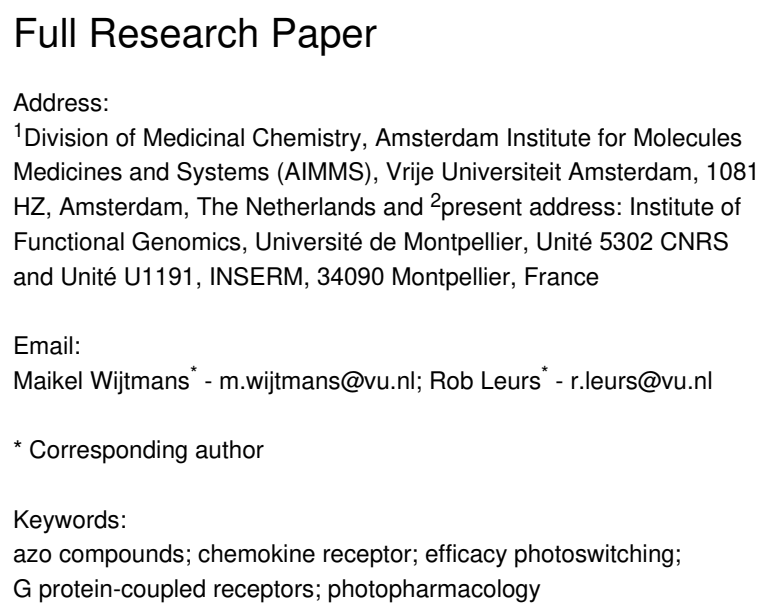

Beilstein J. Org. Chem. 2019, 15, 2509-2523.

doi:10.3762/bjoc. 15.244

Received: 14 July 2019

Accepted: 27 September 2019

Published: 23 October 2019

This article is part of the thematic issue "Molecular switches".

Guest Editor: W. Szymanski

(C) 2019 Gómez-Santacana et al.; licensee Beilstein-Institut. License and terms: see end of document.

\begin{abstract}
We report a detailed structure-activity relationship for the scaffold of VUF16216, a compound we have previously communicated as a small-molecule efficacy photoswitch for the peptidergic chemokine GPCR CXCR3. A series of photoswitchable azobenzene ligands was prepared through various synthetic strategies and multistep syntheses. Photochemical and pharmacological properties were used to guide the design iterations. Investigations of positional and substituent effects reveal that halogen substituents on the ortho-position of the outer ring are preferred for conferring partial agonism on the cis form of the ligands. This effect could be expanded by an electron-donating group on the para-position of the central ring. A variety of efficacy differences between the trans and cis forms emerges from these compounds. Tool compounds VUF15888 (4d) and VUF16620 (6e) represent more subtle efficacy switches, while VUF16216 (6f) displays the largest efficacy switch, from antagonism to full agonism. The compound class disclosed here can aid in new photopharmacology studies of CXCR3 signaling.
\end{abstract}

\section{Introduction}

Photopharmacology is an emerging discipline at the interface of medicinal chemistry and photochemistry. Classical medicinal chemistry approaches make use of small-molecule ligands binding a target protein, thereby modifying its activity.
Photopharmacological approaches use light-sensitive photochromic ligands that provide an advantageous and more precise pharmacological alternative, especially with respect to spatial and temporal precision [1,2]. Photochromic ligands usually 
contain a molecular photoswitch (photoswitchable moiety) that under certain wavelengths of illumination undergoes an isomerization event, thereby changing the properties of the molecule and the binding affinity for the target protein [3-5] or the intrinsic functional activity (efficacy) [6,7]. Despite the considerable number of photoswitches reported to date, such as spiropyrans, diarylethenes, fulgides or azobenzenes, the most widely used moiety in the photopharmacology is the latter one. One of the main reasons is that an azobenzene has a relatively simple structure that can resemble various biaryl moieties of bioactive compounds: two aromatic rings linked with a bridge (e.g., amide, ether, alkane or alkyne) [8]. In the case of azobenzene the bridge is a diazene group (also called azo group) and depending on the wavelength of illumination, a linear transisomer or a bent $c i s$-isomer can be obtained [9]. If certain biaryl moieties are replaced by an azobenzene (i.e., azologization approach), there is a relatively good chance that one of the resulting photoisomers will have a spatial disposition similar to the original biaryl unit and, therefore, a similar biological activity that might change upon isomerization of the azobenzene [8]. The second reason for the success of azobenzene in the photopharmacology field is the robust photoisomerization. It provides typically high yields of photoisomerization with relatively low intensity of light and minimal photobleaching even over hundreds of cycles. A third reason is the relatively high synthetic accessibility to azobenzenes. All these properties make azobenzene compounds ideal molecular photoswitches to control protein activity and physiological events with light.

A number of protein targets have been explored with photochromic small-molecule ligands, such as ion channels, microtubules, enzymes and GPCRs (G protein-coupled receptors) $[1,10]$. We focus our photopharmacology research on GPCRs $[3,7,11]$, which constitute a superfamily of membrane proteins that regulate many physiological processes [12]. Despite the high relevance of GPCRs both functionally and as a drug target [12], the first synthetic GPCR photochromic small-molecule ligands appeared only five years ago [13-15]. Since then, photopharmacology has been explored on GPCRs targeted endogenously by small molecules $[3,4,11,16-20]$, small peptides [5,13] and larger peptides [7,21,22]. Most of the targeted GPCRs belong to the three rhodopsin-, secretin- and glutamate-like subfamilies and involve GPCRs that endogenously bind small-molecule ligands [10]. The ensuing photochromic GPCR ligands are usually orthosteric and the photoswitching generally affects the functional potency $[4,11,23]$ and/or the binding affinity [3-5,11] of the ligand (Figure 1A). However, as mentioned, GPCRs that endogenously bind large molecules (large peptides or proteins) can be also targeted by allosteric photochromic ligands. In an initial communication [7], we recently reported a photochromic ligand class that is based on azologization of a biaryl ligand class [24] and that activates the chemokine CXCR3 receptor (CXCR3), a GPCR endogenously activated by large peptides CXCL9, CXCL10 and CXCL10 and involved in inflammatory responses. In fact, the six compounds reported in that study represent the first photochromic small-molecule class that harbors a dynamic efficacy photoswitch (from antagonism to agonism) on a peptidergic GPCR (Figure 1B). Here, we report the rationale and synthetic strategies behind this series of compounds, a detailed analysis of the molecular determinants that control the efficacy of the ligands (SAR, structure-activity relationship) and a toolbox of pharmacologically useful photoswitchable small-molecule CXCR3 agonists.

\section{Results and Discussion Azologization design}

The chemokine receptor CXCR3 is endogenously activated by the chemotactic peptides CXCL11, CXCL10 and CXCL9. Synthetic small-molecule ligands can also bind to CXCR3 [25]. Multiple small-molecule CXCR3 antagonist scaffolds have been disclosed but small-molecule CXCR3 agonists are scarce and are mostly limited to peptidomimetics [25], which makes our published biaryl series a notable exception [24]. The general scaffold of these biaryl ligands consists of a polycycloaliphatic anchor and a biaryl moiety both linked to an ammonium ion. Depending on the substitution pattern of this biaryl moiety, a broad spectrum of efficacies for CXCR3 can be obtained, i.e., from antagonists to partial agonists and full agonists (Figure 1C) [24]. Meta and para-substitution yields antagonists (exemplified by 1a,b), while ortho-substitution with halogen atoms provides agonists, exemplified by partial agonist $\mathbf{1 c}$ and equal full agonists 1d and 1e (VUF11418, Figure 2A). A tentative explanation for this efficacy switch includes a variation of the dihedral angle of the biaryl moiety, an increase of the electron density in the biaryl unit and/or a postulated halogen bond of the halogen substituent to the binding site of the receptor [24].

In order to obtain an efficacy photoswitching, we opted for replacing the biaryl moiety for an azobenzene in an azologization approach (Figure 1D) with the expectation that the isomerization of the azobenzene would provide changes in 3D shape that are similar to those observed in the biaryl series. To reinforce this hypothesis, molecular alignments were performed with Molecular Operating Environment (MOE) software [26] in which 1e was used as a model for full agonism (Figure 2). Its 3D structure was superposed with both the trans and cisisomers of parent azobenzene compound 2a allowing flexibility of the molecules except for the conformation of the trans and cis-azobenzene moieties, which were fixed in the lowest energy conformation to ensure a shape that has also been vali- 
A
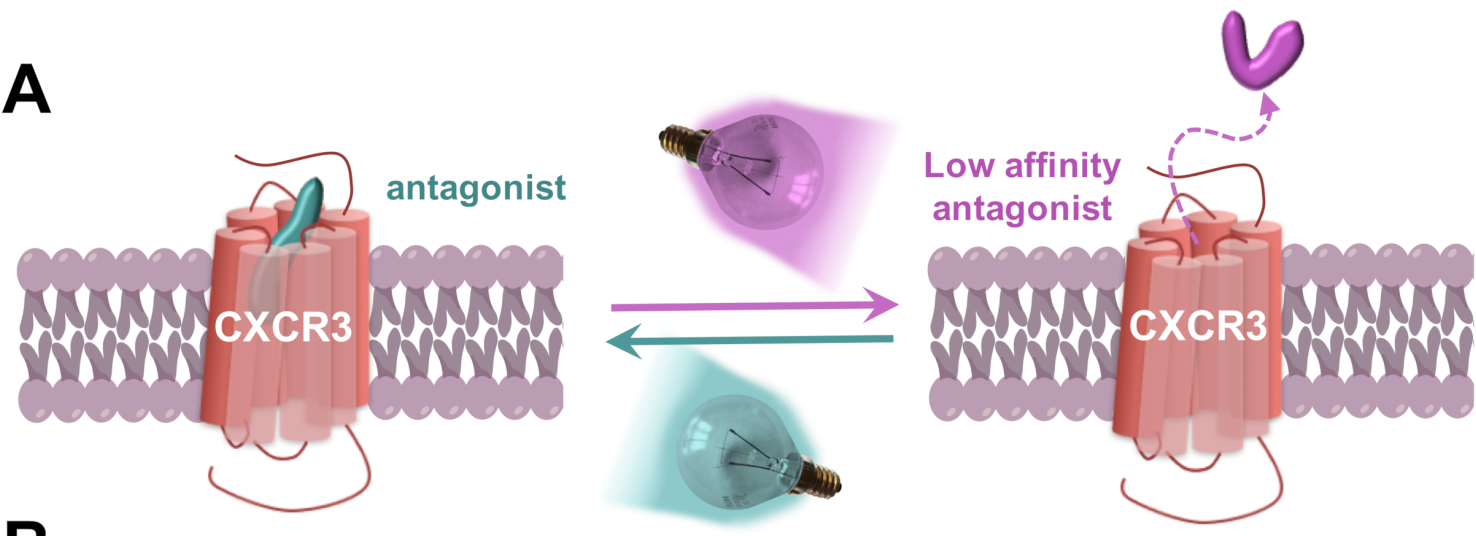

B
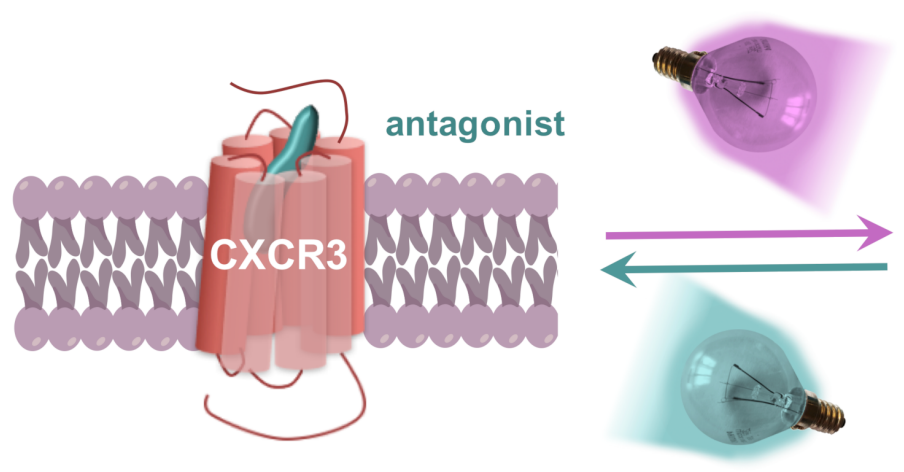

\section{C}

\section{Scaffold for azologization}

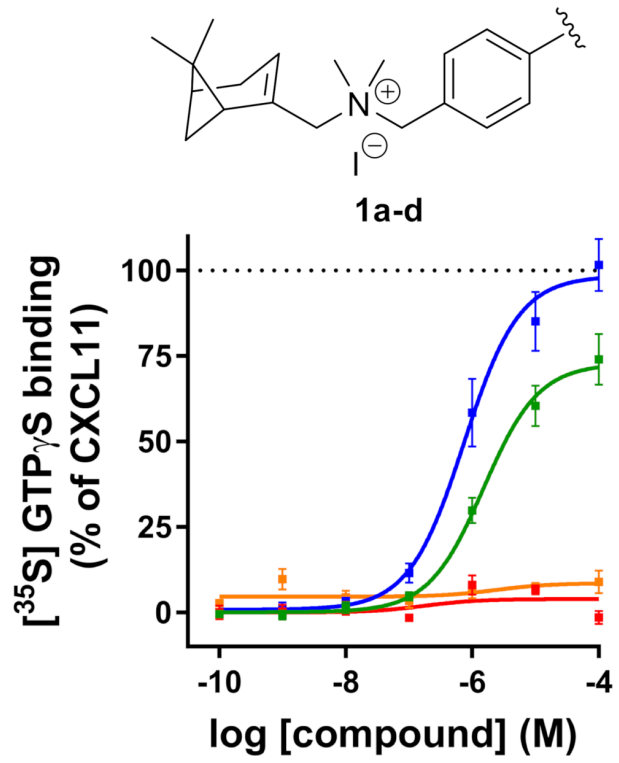<smiles>CCc1ccccc1Br</smiles>

1d

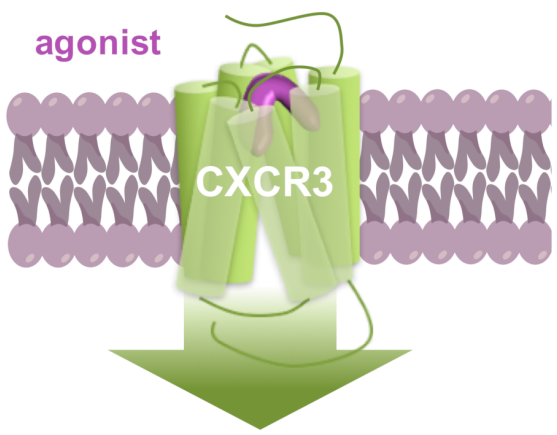

D<smiles>[X]c1ccccc1N=Nc1ccc([N+](C)(C)CC2=CC(C)C(C)(C)C2)c([Y])c1</smiles><smiles>CCCCCOc1cccc(CCC)c1</smiles><smiles>[Y]c1cc(N=Nc2ccccc2[X])ccc1C[N+](C)(C)CC1=CCC(C)(C)C1</smiles>

cis-2-6

Figure 1: Design of the CXCR3 efficacy photowitchable ligands. A,B) Schematic representation of a GPCR photochromic ligand that photoisomerizes and thereby photoswitches (A) binding affinity and/or (B) functional efficacy. Red represents the inactive GPCR, while green represents the active GPCR. C) General structure and exemplary functional dose-response curves of the parent biaryl family of CXCR3 ligands disclosed in Wijtmans et al. [24], in which ortho substitution on the outer aromatic ring gives partial or full agonists, while meta substitution provides antagonists. D) Azologization of the biaryl moiety provides a family of photowitchable CXCR3 small-molecule ligands. 


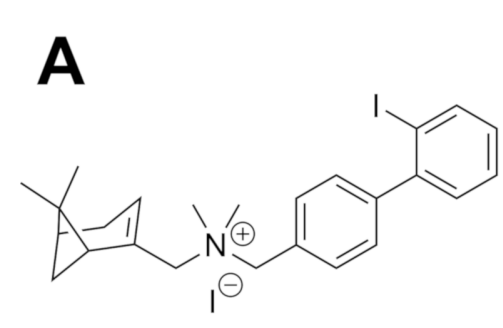

$1 \mathrm{e}$

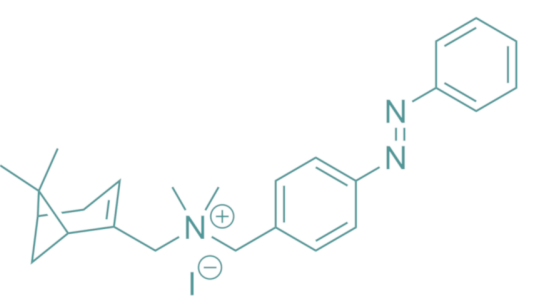

trans-2a

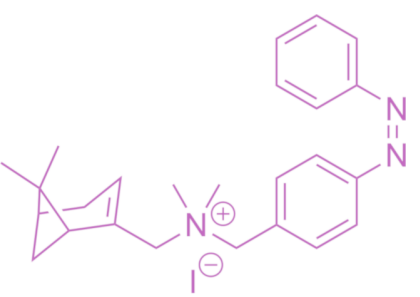

cis-2a

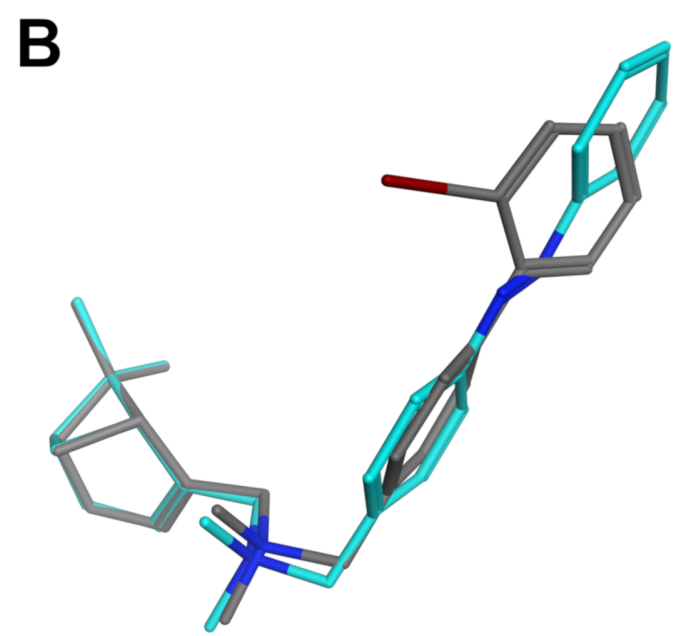

C

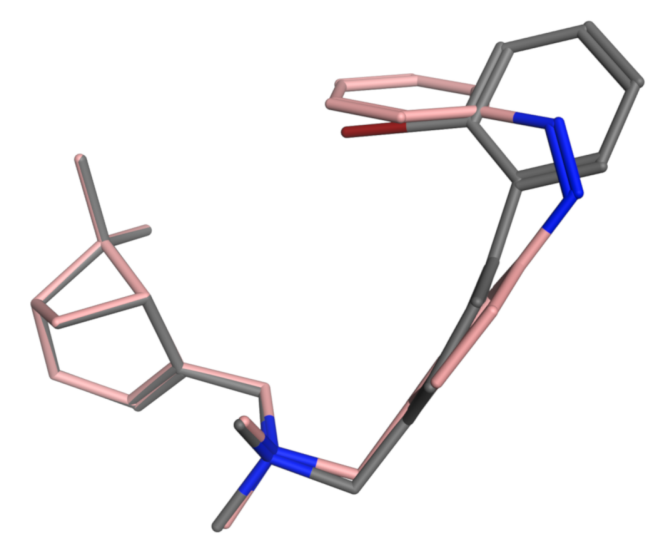

Figure 2: Conformational alignment of a biaryl CXCR3 agonist with a designed azobenzene analogue. A) 2D structure of biaryl CXCR3 agonist 1e and designed ligand trans-2a and cis-2a. B,C) Alignments of 1 e (grey carbon atoms) and $\mathbf{2 a}$, in which the trans and cis-isomers are shown in (B) turquoise and $(C)$ light magenta carbon atoms, respectively. The iodine atom is shown in red for clarity.

dated by crystallographic data [27]. The results show a reasonable overall alignment between trans-2a and the agonist $\mathbf{1 e}$ (Figure 2B), since the planar azobenzene is partially overlapping with the biaryl moiety. However, the two aromatic rings of both compounds can evidently not be in exactly the same plane because the azobenzene moiety is planar while the tilting of the dihedral angle of the biaryl moiety of 1e was speculated to be associated with its agonist activity (vide supra) [24]. The alignment of the cis-isomer of $\mathbf{2 a}$ with agonist $\mathbf{1 e}$ is very different. The outer aromatic ring of cis-2a goes out of plane and is now occupying the space that is also occupied by the iodine atom of 1e. These calculations indicate that CXCR3 agonism is more likely to be associated with the cis-isomer than with the transisomer in our designed azobenzenes.

\section{Synthesis of azobenzene analogues and exploration of substitution pattern on the outer aromatic ring}

In addition to unsubstituted azobenzene analogue $\mathbf{2 a}$, we explored the substitution pattern of the outer aromatic ring with chlorine atoms in the ortho, meta and para-position (compounds $\mathbf{2 b}-\mathbf{d}$, respectively) to also assess the possibility of agonism provided by a halogen bond. Compound $\mathbf{2 e}$, which contains a bromine atom in the ortho-position, was also tested since this atom type provides full agonist activity of parent $\mathbf{1 d}$. The synthesis of the compounds $\mathbf{2 a - e}$ was performed according to the strategies depicted in Scheme 1. The intermediate 7 was prepared as described previously by us [28] and was used in a reductive amination with 4-nitrobenzaldehyde (8a) to give the corresponding tertiary amine $\mathbf{9 a}$ in high yield. The nitro group of $9 \mathbf{a}$ was subsequently reduced by $\mathrm{SnCl}_{2}$ in high yield. The resulting aniline 10a was used to obtain the azo compounds 12a-e in varying yields through a Mills reaction with the corresponding nitroso compounds $\mathbf{1 1 a - e}$, which were commercially available or prepared as described in our previous communication [7]. A final methylation of the tertiary amine 12a-e with MeI in DCM and subsequent precipitation with MTBE (methyl tert-butyl ether) gave $\mathbf{2 a - e}$ as orange powders with $\geq 99 \%$ transisomer in moderate to high yield.

Next, we characterized the photochemical properties of 2a-e, including absorption maxima, wavelengths of illumination and percentage of conversion from trans to cis in the photostationary state (PSS cis). First, UV-vis absorption spectra were measured in the dark and after illumination with a wavelength of $360 \mathrm{~nm}$. In all cases the spectrum measured in the dark 


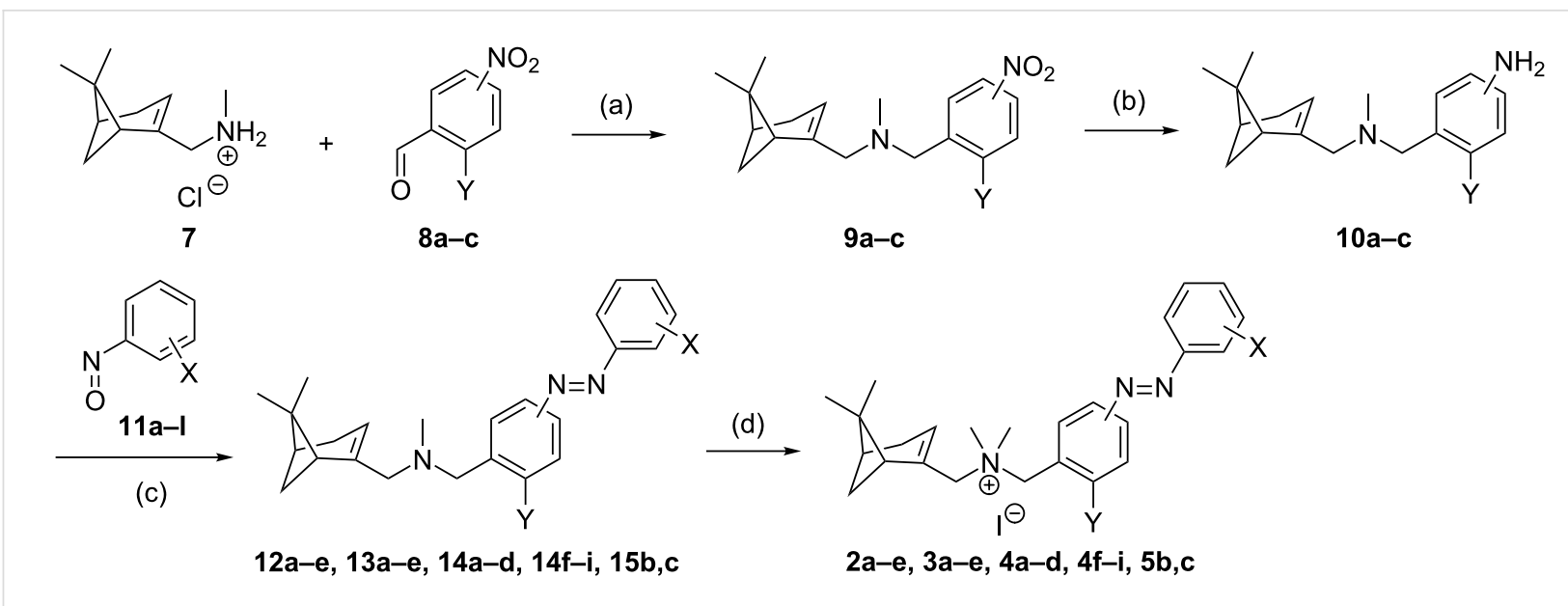

Scheme 1: Synthetic strategies for compounds $\mathbf{2 a - e , ~ 3 a - e , ~} \mathbf{4 a - d}, \mathbf{4} \mathbf{f}-\mathbf{i}$ and $\mathbf{5 b} \mathbf{b} \mathbf{c}(\mathbf{Y}=\mathrm{H}, \mathrm{Cl})$. Reagents and conditions: (a) i) Et $\mathrm{t}_{3} \mathrm{~N}(1.1-1.6$ equiv),

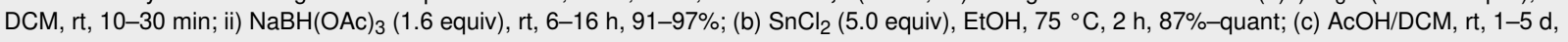
$23-73 \%$, (d) Mel (20 equiv), DCM, rt, 6-72 h, 41-97\%.

shows a large band between 320 and $330 \mathrm{~nm}$ that corresponds to the $\pi-\pi^{*}$ transition of the trans-isomer (Figure S1A, Supporting Information File 1). After irradiating with different wavelengths, the proportion of trans and cis-isomer varies to reach the PPS. For example, after irradiating with $360 \mathrm{~nm}$ the $\pi-\pi^{*}$ transition band of the trans-isomer can barely be observed, but a less intense wide band around $420 \mathrm{~nm}$ appears, which corresponds to the $\mathrm{n}-\pi^{*}$ transition of the $c i s$-isomer (Figure S1A, Supporting Information File 1). This indicates that, using $360 \mathrm{~nm}$ light, a PPS of high percentage of $c i s$-isomer $\left(\mathrm{PPS}_{360}\right)$ can be reached. Literature evidence $[7,29,30]$ suggests that this scaffold would have sufficiently long half-lives of the PSS state, i.e., the cis-isomer only slowly reverts to trans in the dark, which was confirmed by early-stage analyses on key compounds (data not shown). In fact, due to this bistable nature, the percentage of each photoisomer can be quantified by analytical chromatography (LC-MS). The integration wavelength $(265 \mathrm{~nm})$ was selected closely to the observed isosbestic point for most compounds to get an indication of mole ratios from the $\mathrm{UV}$ area ratios. For 2a-e after illumination at $360 \mathrm{~nm}, \mathrm{PPS}_{360}$ values of $79-90 \%$ of $c i$-isomer were obtained. We also tested 434, $460 \mathrm{~nm}$ and/or $494 \mathrm{~nm}$ to revert the isomerization process to PSS trans (Figure S1A, Supporting Information File 1). After re-illuminating the samples at $434 \mathrm{~nm}$ or $460 \mathrm{~nm}$, the $\pi-\pi^{*}$ transition band of the trans-isomer re-appears, indicating a high percentage of trans-isomer at that PSS. The use of $494 \mathrm{~nm}$ affords less trans compound and is less efficient in achieving PSS trans.

Next, the CXCR3 binding properties of 2a-e were measured (Table 1) in a competition binding assay versus displacement of a radiolabeled small-molecule CXCR3 antagonist $\left(\left[{ }^{3} \mathrm{H}\right]-\right.$ VUF11211 [31]). Values reported are mean \pm SEM (Stan- dard Error of the Mean). These experiments were performed with samples under dark conditions to ensure $\geq 99 \%$ transisomer and with samples previously illuminated with $360 \mathrm{~nm}$ light to obtain a high percentage of cis compound in the $\mathrm{PSS}_{360}$. This assay setup is enabled by the bistable nature of the photoswitch (vide supra), maintaining integrity of both the trans and cis-isomer for the duration of the assay. Compounds 2a-e under dark conditions (trans-isomers) bind CXCR3 with $K_{\mathrm{i}}$ values in the high nanomolar range. In contrast, compounds $\mathbf{2 a - e}$ after $360 \mathrm{~nm}$ illumination bind CXCR 3 with $K_{\mathrm{i}}$ values in the low micromolar range, although the observed photoinduced affinity shifts (PAS) are not large ( $<4.0$-fold). To assess if the compounds have agonist or antagonist activity on CXCR3-mediated signaling, a single-dose functional $\left[{ }^{35} \mathrm{~S}\right]-\mathrm{GTP} \gamma \mathrm{S}$ accumulation assay was performed with the compounds $2 \mathbf{a}-\mathbf{e}$ at $10 \mu \mathrm{M}$ (Table 1). In this assay, we observed that most of the compounds are not activating the CXCR3 receptor in either $c$ is or trans configuration, which indicates that the compounds bind to the receptor as antagonists. However, cis-2b and, more notably, cis-2e show a small partial agonist activity $(11 \%$ and $23 \%$, respectively) that gives a hint of a slight photoswitching of their efficacy. Both compounds have a halogen atom on the orthoposition of the outer ring, which seems to reaffirm the importance of the ortho-halogen atoms effect observed in the biaryl series [24]. However, the difference in efficacy between cis and trans-isomers (defined as PDE - photoinduced difference of efficacy) needed to be improved.

\section{Optimization of positioning of azobenzene unit}

Aiming to improve the position and directionality of the halogen atom, we next designed a subseries with the azo group at the meta-position of the central ring (scaffold $\mathbf{3}$ ) instead of at 
Table 1: Structures and results of photochemical, binding and functional characterization of compounds $2 \mathbf{a}-\mathbf{e}$ and $3 \mathbf{a}-\mathbf{h}$.

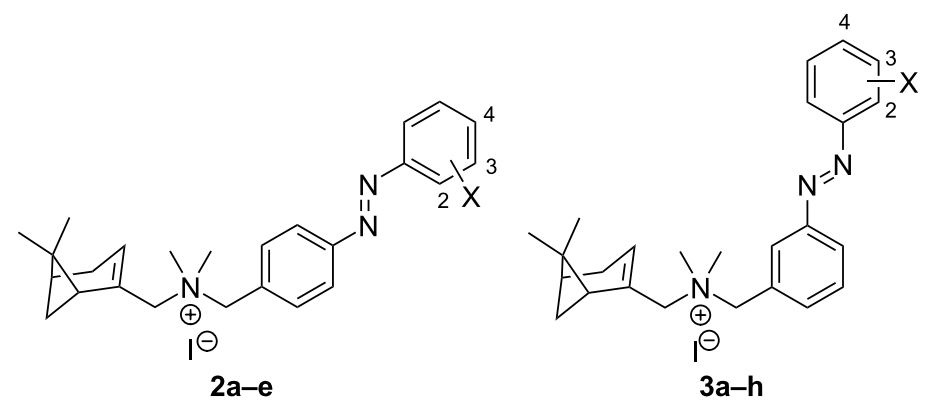

\begin{tabular}{|c|c|c|c|c|c|c|c|c|c|c|c|c|c|c|c|}
\hline \multirow[b]{2}{*}{ Cmpd } & \multirow[b]{2}{*}{$x$} & \multicolumn{3}{|c|}{ Photochemistry } & \multicolumn{6}{|c|}{ CXCR3 binding affinity } & \multicolumn{5}{|c|}{ Functional CXCR3 activity } \\
\hline & & $\begin{array}{c}\lambda_{\max } \\
\text { trans } \\
\Pi-\Pi^{*} \mathrm{a}\end{array}$ & $\begin{array}{c}\lambda_{\max } \\
\text { cis } \\
\mathrm{n}-\Pi^{*} \mathrm{a}\end{array}$ & $\begin{array}{c}\mathrm{PSS}_{360} \\
(\text { area \% } \\
\text { cis) }\end{array}$ & SEM & $\underset{\text { trans }^{\mathrm{c}}}{\mathrm{p} K_{\mathrm{i}}}$ & SEM & $\begin{array}{c}\mathrm{pK}_{\mathrm{i}} \\
\mathrm{PSS}_{360^{\mathrm{C}}}\end{array}$ & SEM & PAS $^{d}$ & $\begin{array}{l}\mathrm{E}(\%) \\
\text { trans }^{\mathrm{e}}\end{array}$ & SEM & $\begin{array}{c}E(\%) \\
P_{S S}{ }_{360}^{f}\end{array}$ & SEM & $\begin{array}{l}\text { PDE } \\
(\%)^{g}\end{array}$ \\
\hline $2 a$ & $\mathrm{H}$ & 321 & 422 & 88.3 & 0.8 & 6.3 & 0.0 & 5.7 & 0.1 & 4.0 & -11.0 & 2.3 & -8.3 & 0.7 & 2.7 \\
\hline $2 b$ & $2-\mathrm{Cl}$ & 323 & 416 & 84.9 & 0.5 & 6.3 & 0.0 & 5.8 & 0.1 & 3.2 & 2.4 & 4.3 & 11.1 & 2.0 & 8.7 \\
\hline 2c & $3-\mathrm{Cl}$ & 320 & 421 & 79.2 & 0.9 & 6.5 & 0.0 & 6.3 & 0.0 & 1.6 & -10.3 & 3.5 & -9.6 & 2.7 & 0.7 \\
\hline $2 d$ & $4-\mathrm{Cl}$ & 330 & 423 & 89.7 & 0.5 & 6.6 & 0.0 & 6.0 & 0.0 & 4.0 & -9.8 & 3.5 & -2.7 & 3.6 & 7.1 \\
\hline $2 e$ & $2-\mathrm{Br}$ & 324 & 421 & 87.2 & 0.5 & 6.4 & 0.0 & 5.9 & 0.1 & 3.2 & 7.0 & 1.6 & 22.7 & 1.5 & 15.7 \\
\hline $3 a$ & $\mathrm{H}$ & 320 & 423 & 82.0 & 1.5 & 6.0 & 0.1 & 5.4 & 0.1 & 4.0 & -11.6 & 2.2 & -4.7 & 1.7 & 6.9 \\
\hline $3 b$ & $2-\mathrm{Cl}$ & 323 & 419 & 85.0 & 0.5 & 6.3 & 0.0 & 5.6 & 0.0 & 5.0 & -4.7 & 1.7 & 17.4 & 3.7 & 22.1 \\
\hline $3 c$ & $3-\mathrm{Cl}$ & 317 & 421 & 83.4 & 0.4 & 6.3 & 0.0 & 5.8 & 0.0 & 3.2 & -8.4 & 2.2 & -0.4 & 1.6 & 8.0 \\
\hline $3 d$ & $4-\mathrm{Cl}$ & 325 & 424 & 92.0 & 0.3 & 6.4 & 0.0 & 5.7 & 0.0 & 5.0 & -8.1 & 2.6 & 1.7 & 2.3 & 9.8 \\
\hline $3 e^{h}$ & $2-\mathrm{Br}$ & 323 & 421 & 88.9 & 0.4 & 6.3 & 0.0 & 5.7 & 0.1 & 4.0 & -5.8 & 1.7 & 25.1 & 2.0 & 30.9 \\
\hline $3 f$ & $2-1$ & 323 & 422 & 80.9 & 0.2 & 6.2 & 0.0 & 5.8 & 0.1 & 2.5 & -4.0 & 1.2 & 15.8 & 1.3 & 19.8 \\
\hline $3 g$ & $3-1$ & 318 & 422 & 82.5 & 1.5 & 6.1 & 0.1 & 6.1 & 0.0 & 1.0 & -11.1 & 0.6 & -7.6 & 2.3 & 3.5 \\
\hline $3 h$ & 4-I & 337 & 422 & 91.1 & 1.1 & 6.0 & 0.0 & 5.7 & 0.0 & 2.0 & -15.3 & 1.1 & 5.4 & 1.5 & 20.7 \\
\hline
\end{tabular}

aThe absorbance maxima were extracted from UV-vis spectra at $25 \mu \mathrm{M}$ in PBS buffer with $1 \% \mathrm{DMSO}$. b\% of cis-isomer at the photostationary state $\left(\mathrm{PSS}_{360}\right)$ measured in $68 \%$ TRIS buffer and $32 \%$ DMSO $(1 \mathrm{mM})$ after being pre-irradiated at $360 \mathrm{~nm}$ as obtained by LC-MS integration of the cis and trans-isomer signals at $265 \mathrm{~nm}$. The mean and SEM of at least two experiments are shown. 'Binding affinity of trans-isomer or PSS 360 as measured using $\left[{ }^{3} \mathrm{H}\right]$-VUF11211 displacement. The mean and SEM of at least three experiments are shown. ${ }^{\mathrm{d}}$ The photoinduced affinity shift (PAS) is calculated

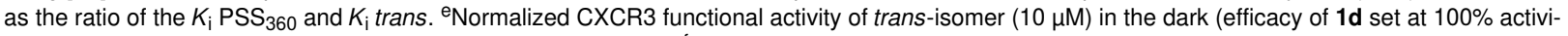
ty). The mean and SEM of at least three experiments are shown. ${ }^{f}$ Normalized CXCR3 functional activity of a sample (10 $\left.\mu \mathrm{M}\right)$ pre-irradiated at $360 \mathrm{~nm}$ to reach the photostationary state (efficacy of 1d set at 100\% activity). The mean and SEM of at least three experiments are shown. ${ }^{9}$ The photoinduced difference of efficacy (PDE) is obtained by subtracting $E$ trans from $E$ PSS $_{360}$. ${ }^{\mathrm{h}}$ Compound was previously described by us [7].

the para-position as in $\mathbf{2 a - e . ~ T h e ~ a n a l o g u e ~ w i t h o u t ~ h a l o g e n ~}$ substitution (3a) as well as $\mathrm{Cl} / \mathrm{Br}$ analogues comparable to the first series (3b-e) were prepared. Moreover, since the importance of the presence of a halogen in the outer ring was suggested in $\mathbf{2}$, compounds $\mathbf{3 f}-\mathbf{h}$, which include an iodine atom on the ortho, meta and para-positions, respectively, were synthesized.

The synthesis of compounds 3a-e was performed following the strategies shown in Scheme 1 as disclosed for compounds 2a-e. Briefly, a reductive amination of $\mathbf{7}$ and $\mathbf{8 b}$ gave nitro compound $\mathbf{9 b}$, which after reduction to $\mathbf{1 0 b}$, coupling with nitroso compounds 11a-e to 13a-e and methylation gave iodide salts 3a-e with purities of trans-isomers $\geq 99 \%$ and overall yields similar to the ones obtained for $\mathbf{2 a - e}$. However, 2-iodonitroso- benzene cannot be accessed through oxidation of the corresponding aniline owing to oxidation sensitivity of the iodine atom. Therefore, an alternative route had to be used to synthesize $\mathbf{3 f}-\mathbf{h}$ (Scheme 2). The route began with the oxidation of methyl 3-aminobenzoate (17a) using Oxone ${ }^{\circledR}$ to obtain a crude nitroso product $\mathbf{1 8 a}$, which was used in a Mills reaction with an iodoaniline $(\mathbf{1 9 a}-\mathbf{c})$ at $100{ }^{\circ} \mathrm{C}$ to obtain azobenzenes $\mathbf{2 0 g}, \mathbf{h}$ in high yields and ortho-analogue $\mathbf{2 0 f}$ in a decreased yield presumably due to steric hindrance. The methyl ester was selectively reduced with DIBAL-H to benzyl alcohols $\mathbf{2 3 f - h}$, which were oxidized with Dess-Martin periodinane to the corresponding

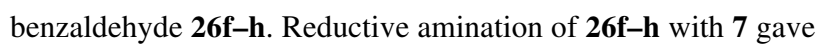
the tertiary amines $\mathbf{1 3 f}-\mathbf{h}$. Methylation with iodomethane and subsequent precipitation gave $\mathbf{3 f}-\mathbf{h}$ as orange powders with $\geq 99 \%$ trans-isomer in high yields. 
<smiles>[X]c1ccc(N=Nc2ccccc2)cc1N=Nc1cccc(N=Nc2ccc([Y])c(C(=O)OC)c2)c1</smiles>

26f-h, 27, 28b, 28d

$13 f-h, 14 e, 16 b, 16 d$

$3 f-h, 4 e, 6 b, 6 d$

Scheme 2: Synthetic strategies for compounds $\mathbf{3 f}-\mathbf{h}, \mathbf{4 e}, \mathbf{6 b}$, and $\mathbf{6 d}(\mathrm{Y}=\mathrm{H}, \mathrm{F}, \mathrm{Cl}, \mathrm{Br})$. Reagents and conditions: (a) Oxone $\AA^{(2.0}$ equiv), DCM/ $\mathrm{H}_{2} \mathrm{O}$ 1:4, rt, $2 \mathrm{~h}, 91-98 \%$; (b) AcOH, $100{ }^{\circ} \mathrm{C}, 16-20 \mathrm{~h}, 61-96 \%$; (c) i) DIBAL-H (3.0-4.0 equiv), THF, $0-5{ }^{\circ} \mathrm{C}$ to rt, $2-4 \mathrm{~h}$; ii) $\mathrm{NH}_{4} \mathrm{Cl}$ (aq), Rochelle salt (10\% aq), EtOAc, $1-2 \mathrm{~h}, 76-99 \%$; or for $23 \mathrm{~h}$ i) DIBAL-H (1.2 equiv), DCM, $-78{ }^{\circ} \mathrm{C}, 1 \mathrm{~h}$; ii) $\mathrm{MeOH},-78{ }^{\circ} \mathrm{C}$ to rt, $0.5 \mathrm{~h}$, iii) Rochelle salt (10\% aq), $3 \mathrm{~h}, 45 \%$; (d) Dess-Martin periodinane (1.0 equiv), DCM, rt, 1-2 h, 68-97\%; (e) i) $\mathrm{Et}_{3} \mathrm{~N}$ (1.1-1.6 equiv), DCM, rt, 10-30 min; ii) $\mathrm{NaBH}(\mathrm{OAc})_{3}$ (1.6 equiv), rt, 6-16 h, 69-96\%; (f) Mel (20 equiv), DCM, rt, 6-72 h, 79-95\%.

The photochemical properties of $\mathbf{3 a - h}$ are very similar to those of $\mathbf{2 a - e . ~ F o r ~ t h e ~ t r a n s - i s o m e r s , ~ t h e ~ m a x i m u m ~ o f ~ t h e ~} \pi-\pi^{*}$ band is located around $317-325 \mathrm{~nm}$, with the exception of $\mathbf{3 h}$ which has an iodine atom on the para-position and arguably confers a larger electron delocalization of $\pi$-electrons that is translated to a bathochromic shifting of the band to lower energy wavelength $(337 \mathrm{~nm})$. PSS values of $81-92 \%$ are obtained when illuminating with $360 \mathrm{~nm}$ light. The binding properties of 3a-h also result in outcomes similar to those of 2a-e. That is, $K_{\mathrm{i}}$ values are in the high nanomolar range for the trans-isomers with no or low PAS values (1.0-5.0-fold) after isomerization. In single-dose functional assays, all trans-isomers do not substantially activate CXCR3, whereas three of the cis-isomers weakly to substantially activate CXCR3 (3b: $17 \%$, 3e: $25 \%$ and 3f: $16 \%$ ). Interestingly, these three compounds are the only ones to include a halogen atom on the ortho-position of the outer azobenzene ring, as is the case with para-compounds $2 \mathbf{b}$ (11\%) and $2 \mathrm{e}(23 \%)$. However, compared to the latter, meta-compounds $\mathbf{3 b}, \mathbf{e}, \mathbf{f}$ display an agonist effect that is slightly higher. Increasing the size of the ortho-halogen does not guarantee a maximal agonist effect, as the absolute activity of $\mathbf{3 f}$ is lower than that of its $\mathrm{Br}$ analogue 3e. Nevertheless, evidence emerged that the ortho-position of the outer aromatic ring in scaffold $\mathbf{3}$ is important to achieve agonist activity of the cis-isomer, but it should be complemented with other strategies to further increase intrinsic activity.

\section{Substituent effects on the outer ring}

One of the postulated contributors to the CXCR3 agonism effect of parent biaryls such as $\mathbf{1 d}$ and $\mathbf{1 e}$ is the increased $\pi$-electron density of the aromatic rings [24]. A way to translate this effect to the azobenzene system is by including a $\pi$-donating substituent on the aromatic system. For synthetic access and thus rapid exploration, we chose a $\mathrm{Cl}$ atom as mildly $\pi$-EDG (electron-donating group) even though it is $\sigma$-EWG (electronwithdrawing group) on the para-position of the inner ring with respect to the azo bond (i.e., the ortho-position with respect to the benzylic position) to afford subseries 4 . This $\pi$-electron delocalization would increase the electron density of the azobenzene unit, and was also expected to have an effect on the trans-cis azobenzene isomerization and PSS value. In terms of the outer ring, and given that ortho halogen atoms in subseries 2 and $\mathbf{3}$ play an important role in conferring the cis-isomer with partial agonism, in subseries 4 we explored halogen atoms and groups differing in, e.g., steric and electronic properties (Me, $\left.\mathrm{CF}_{3}, \mathrm{OMe}, \mathrm{OCF}_{3}\right)$. The electron-donating groups in this series (Me and $\mathrm{OMe}$ ) also increase the electron density of the azobenzene system.

The synthesis of $\mathbf{4 a - d}$ and $\mathbf{4 f - i}$ was performed following the route shown in Scheme 1. Briefly, 7 was used in a reductive amination with 2-chloro-3-nitrobenzaldehyde $(\mathbf{8 c})$ to give nitro compound $9 \mathrm{c}$ which was reduced to aniline $10 \mathrm{c}$ and used to 
obtain the azo compounds $\mathbf{1 4 a - d , f - i ~ i n ~ v a r i a b l e ~ y i e l d s ~ t h r o u g h ~}$ a Mills reaction with the corresponding nitroso compounds 11ab,e-j. Methylation of 14a-d,f-i with MeI yielded compounds 4a-d,f-g,i as orange powders with $\geq 99 \%$ trans-isomer in moderate to high yields. Salt $\mathbf{4 h}$ did not precipitate after treatment with MTBE and was isolated as an oil, which retained substantial amounts of MTBE solvate even after extensive drying. For $\mathbf{4 e}$, we used the strategy as explained for iodo compounds $\mathbf{3 f}-\mathbf{h}$ (vide supra). Briefly, the route (Scheme 2) consists of the oxidation of methyl 5-amino-2-chlorobenzoate (17c) with Oxone ${ }^{\circledR}$ to $\mathbf{1 8 c}$, which was used in a Mills reaction with 2-iodoaniline (19a) to yield azobenzene 21. The methyl ester was selectively reduced with DIBAL-H and the resulting alcohol $\mathbf{2 4}$ oxidized with Dess-Martin periodinane to benzaldehyde 27. Reductive amination of 27 with 7 to $14 \mathrm{e}$ and subsequent methylation gave 4e as an orange powder with $\geq 99 \%$ trans-isomer.

Photochemical characterization of $\mathbf{4 a - i}$ (Table 2) gives similar results as observed for subseries $\mathbf{2}$ and $\mathbf{3}$ (Figure S2 (Supporting Information File 1) shows an exemplary time-resolved NMR and LC-MS analysis). That is, trans $\pi-\pi^{*}$ bands have a maximum between 326 and $332 \mathrm{~nm}$ and PSS values generally amount to over $90 \%$ of $c i s$-isomer after illuminating with $360 \mathrm{~nm}$ light, as predicted from the electron localization provided by the chlorine atom in the central aromatic ring. Compounds $4 \mathbf{e}, \mathbf{4} \mathbf{i}$ and most notably $\mathbf{4 g}$ deviate from this trend, since the percentage of $c i s$-isomer in the PSS is significantly lower (58-80\%). Trans-4a-i show a slight decrease in binding affinity

Table 2: Structure and results of photochemical, binding and functional characterization of compounds $4 \mathbf{a}-\mathbf{i}$ and $\mathbf{5 b}, \mathbf{c}$.

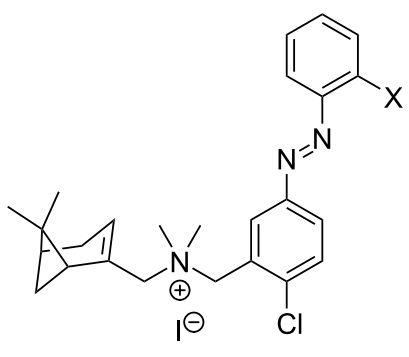

4a-i<smiles>CC1(C)CCC2CC1CC2C[N+](C)(C)Cc1cc(N=NC2=CC=CC=[Se]2Br)ccc1Cl</smiles>

$4 d, 5 b, c$

\begin{tabular}{|c|c|c|c|c|c|c|c|c|c|c|c|c|c|c|c|}
\hline \multirow[b]{2}{*}{ Cmpd } & \multirow[b]{2}{*}{$x$} & \multicolumn{3}{|c|}{ Photochemistry } & \multirow[b]{2}{*}{ SEM } & \multicolumn{5}{|c|}{ CXCR3 binding affinity } & \multicolumn{5}{|c|}{ Functional CXCR3 activity } \\
\hline & & $\begin{array}{c}\lambda_{\max } \\
\text { trans } \\
\Pi_{-\Pi^{*}} \mathrm{a}\end{array}$ & $\begin{array}{c}\lambda_{\max } \\
\text { cis } \\
\mathrm{n}-\Pi^{*} \mathrm{a}\end{array}$ & $\begin{array}{c}\mathrm{PSS}_{360} \\
\text { (area \% }_{\text {cis })^{\mathrm{b}}}\end{array}$ & & $\underset{\text { trans }^{\mathrm{c}}}{\mathrm{p} K_{\mathrm{i}}}$ & SEM & $\begin{array}{c}\mathrm{p} K_{\mathrm{i}} \\
\mathrm{PSS}_{360^{\mathrm{C}}}\end{array}$ & SEM & PAS $^{d}$ & $\begin{array}{l}\mathrm{E}(\%) \\
\text { trans }^{\mathrm{e}}\end{array}$ & SEM & $\begin{array}{c}E(\%) \\
\text { PSS }_{360}{ }^{f}\end{array}$ & SEM & $\begin{array}{l}\text { PDE } \\
(\%)^{9}\end{array}$ \\
\hline $4 a$ & $\mathrm{H}$ & 326 & 424 & 91.8 & 1.2 & 5.8 & 0.0 & 5.2 & 0.0 & 4.0 & -2.9 & 1.0 & 12.1 & 0.7 & 15.0 \\
\hline $4 b$ & $2-\mathrm{F}$ & 330 & 420 & 93.0 & 0.2 & 5.6 & 0.0 & 5.0 & 0.0 & 4.0 & -4.9 & 0.5 & 14.6 & 0.8 & 19.5 \\
\hline 4c & $2-\mathrm{Cl}$ & 330 & 419 & 92.8 & 0.1 & 5.8 & 0.0 & 5.3 & 0.1 & 3.2 & 2.3 & 1.6 & 36.9 & 2.0 & 34.6 \\
\hline $4 d^{h}$ & $2-\mathrm{Br}$ & 328 & 422 & 92.6 & 0.2 & 5.9 & 0.0 & 5.6 & 0.0 & 2.0 & 13.6 & 2.4 & 49.6 & 2.6 & 36.0 \\
\hline $4 e$ & $2-I$ & 330 & 424 & 79.9 & 1.2 & 5.7 & 0.0 & 5.7 & 0.0 & 1.0 & 16.0 & 1.4 & 37.1 & 0.5 & 21.1 \\
\hline $4 f$ & 2-Me & 332 & 428 & 94.9 & 0.1 & 5.9 & 0.0 & 5.3 & 0.0 & 4.0 & 6.9 & 3.1 & 32.2 & 1.1 & 25.3 \\
\hline $4 g$ & $2-\mathrm{CF}_{3}$ & 326 & 424 & 58.0 & 1.1 & 5.9 & 0.0 & 5.7 & 0.0 & 1.6 & 10.5 & 1.6 & 8.3 & 1.5 & -2.2 \\
\hline $4 h$ & 2-OMe & 328 & 427 & 92.6 & 0.2 & 5.4 & 0.0 & 5.0 & 0.0 & 2.5 & 4.9 & 1.2 & 18.7 & 1.1 & 13.8 \\
\hline $4 i$ & $2-\mathrm{OCF}_{3}$ & 326 & 422 & 78.8 & 1.2 & 5.9 & 0.0 & 5.6 & 0.0 & 2.0 & -3.0 & 2.0 & -2.4 & 3.1 & 0.6 \\
\hline $4 d^{h}$ & $2-\mathrm{Br}$ & 328 & 422 & 92.6 & 0.2 & 5.9 & 0.0 & 5.6 & 0.0 & 2.0 & 13.6 & 2.4 & 49.6 & 2.6 & 36.0 \\
\hline $5 b$ & $3-\mathrm{Br}$ & 324 & 420 & 87.4 & 1.2 & 5.7 & 0.1 & 5.6 & 0.0 & 1.3 & -1.7 & 1.9 & 10.5 & 0.5 & 12.2 \\
\hline $5 c$ & $4-\mathrm{Br}$ & 335 & 427 & 93.8 & 0.5 & 6.2 & 0.0 & 5.6 & 0.0 & 4.0 & -7.2 & 1.8 & 1.8 & 2.5 & 9.0 \\
\hline
\end{tabular}

aThe absorbance maxima were extracted from UV-vis spectra at $25 \mu \mathrm{M}$ in PBS buffer with $1 \% \mathrm{DMSO}$. b\% of cis-isomer at the photostationary state $\left(\mathrm{PSS}_{360}\right)$ measured in $68 \%$ TRIS buffer and $32 \%$ DMSO $(1 \mathrm{mM})$ after being pre-irradiated at $360 \mathrm{~nm}$ as obtained by LC-MS integration of the cis and trans-isomer signals at $265 \mathrm{~nm}$. The mean and SEM of at least two experiments are shown. 'Binding affinity of trans-isomer or PSS 360 in PBS $(25 \mu \mathrm{M})$ as measured using $\left[{ }^{3} \mathrm{H}\right]$-VUF11211 displacement. The mean and SEM of at least three experiments are shown. ${ }^{\mathrm{d}}$ The photoinduced affinity shift (PAS) is calculated as the ratio of the $K_{\mathrm{i}} \mathrm{PSS}_{360}$ and $K_{\mathrm{i}}$ trans. ${ }^{e}$ Normalized CXCR3 functional activity of trans-isomer $10 \mu \mathrm{M}$ in the dark (efficacy of $\mathbf{1 d}$ set at $100 \%$ activity). The mean and SEM of at least three experiments are shown. ${ }^{\mathrm{f}}$ Normalized CXCR3 functional activity of a sample (10 $\mu \mathrm{M}$ ) pre-irradiated at $360 \mathrm{~nm}$ to reach the photostationary state (efficacy of $\mathbf{1 d}$ set at $100 \%$ activity). The mean and SEM of at least three experiments are

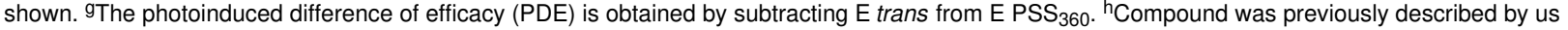
[7]. 
compared to the subseries $\mathbf{2}$ and $\mathbf{3}$, amounting to low micromolar values (Table 2). Moreover, PSS affinity values are also modest, with only four compounds that have a PAS $>2.5$ (4a-c,f). However, functional data from $\left[{ }^{35} \mathrm{~S}\right]-\mathrm{GTP} \gamma \mathrm{S}$ assays provide encouraging results. While all trans-isomers of $\mathbf{4 a - i}$ do not or only weakly activate the receptor, some of the cisisomers clearly behave as partial agonists. The highest efficacy is exerted by cis-4c-f with E values between $30-50 \%$ at $10 \mu \mathrm{M}$. Interestingly, one of these compounds (4f) includes a methyl group as ortho-substituent on the outer ring and its agonist effect at PSS amounts to $32 \%$, possibly questioning one of our hypotheses that a halogen bond is involved in inducing CXCR3 agonism.

Similar to subseries $\mathbf{3}$, the substituent on the ortho-position of the outer aromatic ring appears to be a driver for the agonist activity of the corresponding cis-isomer. Starting from weak partial agonist $4 \mathbf{a}(\mathrm{X}=\mathrm{H})$, the agonist response of the cis increases with increasing halogen atom $(\mathbf{4 b}-\mathbf{d})$ to a maximal response with $\mathbf{4 d}(\mathrm{X}=\mathrm{Br})$ having an agonist effect of $50 \%$. However, when $\mathrm{X}=\mathrm{I}(\mathbf{4 e})$ the agonist activity is reduced, as also observed in the $\mathbf{3}$ subseries (compare $\mathbf{3 d}$ to $\mathbf{3 e}$ ). In general, the agonist effects and PDE values exerted by subseries $\mathbf{4}$ are larger than those of $\mathbf{3}$ (Figure 3). This could be explained by the effect of the $\mathrm{Cl}$ atom present in the $\mathbf{4}$ subseries, that may give a rise in electron density to the azobenzene necessary to increase the efficacy of the cis-isomer.

In both subseries $\mathbf{3}$ and $\mathbf{4}$, a bromine atom on the ortho-position of the outer ring gives optimal results in providing CXCR3 efficacy photoswitching (Figure 3). To confirm this for subseries 4 , the analogues of $\mathbf{4 d}$ with the bromine on the meta and para position (5b and $\mathbf{5 c}$, respectively) were also synthesized. The synthetic route (Scheme 1) utilized 10c and 3- and 4-bromonitroso- benzene $(11 \mathbf{k}, \mathbf{l})$ to form azobenzenes $15 \mathbf{b}, \mathbf{c}$, which were methylated to obtain $\mathbf{5 b}$,c. The binding affinities (Table 2) obtained for the trans and cis-isomers are all in the micromolar range. More importantly, when comparing functional results of 4d, $\mathbf{5 b}$ and $\mathbf{5 d}$, the preference for a $\mathrm{Br}$ atom on the ortho-position can also be reaffirmed for subseries $\mathbf{4}$, because cis-5c is an antagonist, while cis-5b shows only a weak activity (Table 2).

\section{Substituent effects on the central ring}

As shown, substitution of the outer ring with an ortho-bromine in conjunction with a $\mathrm{Cl}$ substituent on the central ring appeared to pave the way for efficacy photoswitching but there was still room for improvement. Our strategy in the final optimization round was to replace the mildly $\pi$-EDG $\mathrm{Cl}$ atom with other groups. Thus, to aim for a full-agonist cis compound, the subseries 6 was synthesized. In this subseries, different groups at the para-position of the central $\operatorname{ring}(\mathrm{Y})$ in combination with the ortho-Br atom on the outer aromatic ring are used to to explore optimal electron densities in the azobenzene system. Besides the $\mathrm{H}$ and $\mathrm{Cl}$ already explored (3e and $\mathbf{4 d}$, respectively), other groups including an EWG halogen atom $(\mathrm{F}, \mathbf{6 b})$, EDG halogen atoms $(\mathrm{Br}, \mathbf{6 d}$ and $\mathrm{I}, \mathbf{6 e})$ and stronger EDG moieties such as $\mathrm{OMe}(\mathbf{6 f}), \mathrm{OiPr}(\mathbf{6 g}), \mathrm{SMe}(\mathbf{6 h})$ and $\mathrm{NMe}_{2}(\mathbf{6 i})$ were introduced.

Compounds $\mathbf{6 b}$ and $\mathbf{6 d}$ were synthesized by the route shown in Scheme 2, using in this case halogenated methyl aminobenzoates $17 \mathbf{b}, \mathbf{c}$ and 2-bromoaniline 19d. The synthetic route for compound $\mathbf{6 e}$ proved more challenging. The route of Scheme 1 could not be readily used because the corresponding iodinated nitro precursor $\mathbf{8}$ is not commercially available, nor could the second route (Scheme 2) since the iodine would likely be sensitive to the first oxidation step. Therefore, we designed a new route (Scheme 3 ). The starting point was the advanced intermediate $\mathbf{2 8 b}$ (Scheme 3), which was subjected to an aromatic

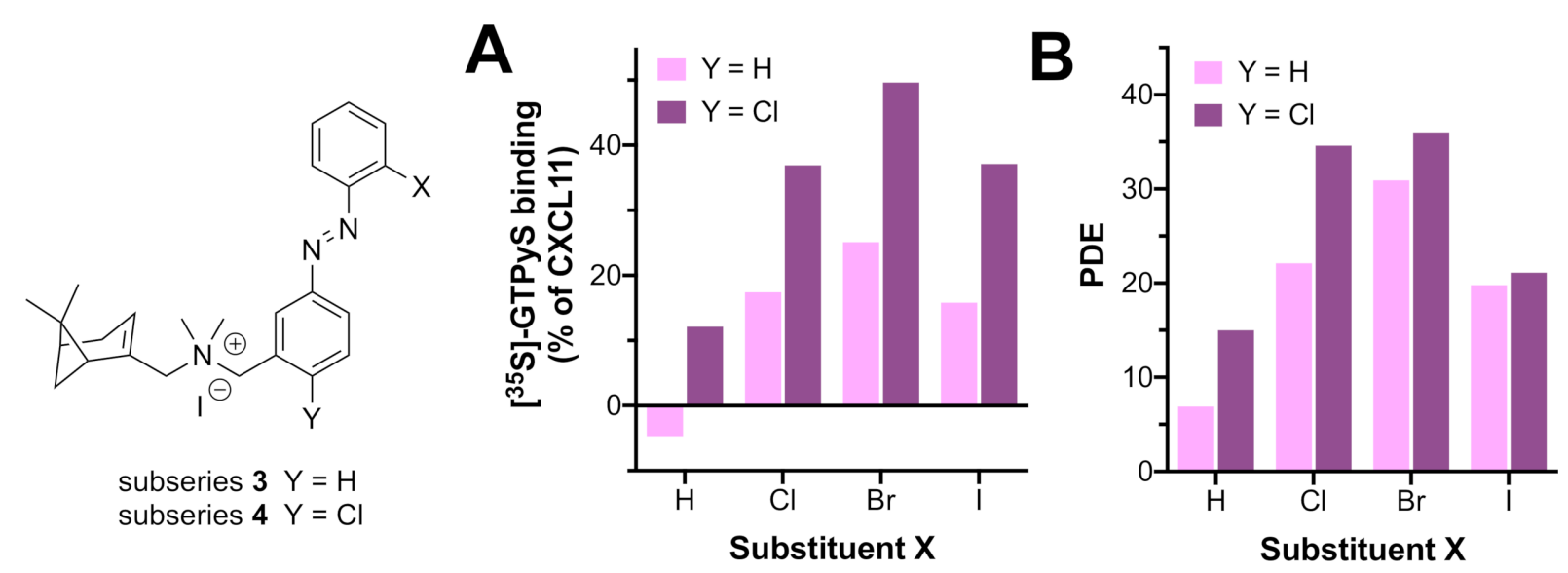

Figure 3: Comparison of compounds belonging to the subseries 3 or $\mathbf{4}$ with a halogen substitution on the ortho-position of the outer ring (X). (A) Activities of cis-isomers at $10 \mu \mathrm{M}$ on CXCR3-mediated G protein activation. (B) PDE values at $10 \mu \mathrm{M}$. 
<smiles>O=Cc1cc(/N=N/c2ccccc2Br)ccc1F</smiles>

28b<smiles>O=C1NC(=O)c2ccccc21</smiles>

(a)<smiles>Nc1ccc(/N=N/c2ccccc2Br)cc1C=O</smiles>

30<smiles>O=Cc1cc(/N=N/c2ccccc2Br)ccc1I</smiles>

$28 \mathrm{e}$<smiles>CN(CC1=CCC2CC1C2(C)C)Cc1cc(N=Nc2ccccc2Br)ccc1I</smiles>

$16 e$ (d)<smiles>CN(Cc1cc(N=Nc2ccccc2Br)ccc1I)CC1CC2CC1CCC2(C)C</smiles>

6e

Scheme 3: Synthetic strategy for compound $6 e$. Reagents and conditions: (a) i) $\mathrm{K}_{2} \mathrm{CO}_{3}\left(2.0\right.$ equiv), DMF, $\mu \mathrm{W}, 65{ }^{\circ} \mathrm{C}, 3 \mathrm{~h}$; ii) $\mathrm{AcOH}$, reflux, $1 \mathrm{~h}, 67 \%$; (b) i) $p \mathrm{TsOH} \cdot \mathrm{H}_{2} \mathrm{O}$ (3.0 equiv), MeCN, $10-15^{\circ} \mathrm{C}$; ii) $\mathrm{NaNO}_{2}$ (2.0 equiv), $\mathrm{KI}$ (2.5 equiv), $\mathrm{H}_{2} \mathrm{O}, 10-15{ }^{\circ} \mathrm{C}$ to rt, $2 \mathrm{~h}, 13 \%$; (c) i) Et ${ }_{3} \mathrm{~N}$ (1.2 equiv), $\mathrm{DCM}, \mathrm{rt}$, $30 \mathrm{~min}$; ii) $\mathrm{NaBH}(\mathrm{OAc})_{3}$ (1.6 equiv), rt, 16 h, 54\%; (f) Mel (20 equiv), DCM, rt, 20 h, $57 \%$.

nucleophilic substitution with potassium phthalimide prepared in situ from 29 and $\mathrm{K}_{2} \mathrm{CO}_{3}$. Presumably due to the alkaline medium, the phthalimide ring was partially opened as detected by HPLC-MS. Upon attempted re-closing under reflux in $\mathrm{AcOH}$, completely deprotection took place and, after purification, aniline $\mathbf{3 0}$ was obtained with high purity. Compound $\mathbf{3 0}$ was used to introduce the iodine atom through a Sandmeyer reaction to give $\mathbf{2 8 e}$ albeit in low yield. Reductive amination with 7 afforded amine 16e followed by methylation to give trans-6e as an orange solid with $97 \%$ purity.

The synthesis of compounds $\mathbf{6} \mathbf{f}-\mathbf{h}$ was performed following a nucleophilic aromatic substitution route on $\mathbf{2 8 b}$ (Scheme 4) since precursors $\mathbf{8}$ or $\mathbf{1 7}$ with the required substituent $\mathrm{Y}$ were not available. We performed nucleophilic aromatic substitutions with the corresponding sodium salts of $\mathrm{MeOH}, 2-\mathrm{PrOH}$ and MeSH under $\mu \mathrm{W}$ irradiation. Both $\mathbf{2 8 f}(\mathrm{Y}=\mathrm{OMe})$ and $\mathbf{2 8 h}$ ( $\mathrm{Y}=\mathrm{SMe}$ ) were formed in high yields, but the conversion of the reaction with $\mathrm{NaOiPr}$ was very low and partially gave reduction of the benzaldehyde. An alternative route utilized a method from Engle et al. proceeding through a tert-butylimine intermediate (31) formed under Dean-Stark conditions [32] This imine was reacted with $\mathrm{NaOiPr}$ to form the ether 32, which was subsequently hydrolyzed to obtain the desired aldehyde $\mathbf{2 8 g}$ in high yield. Reductive amination of the aldehydes $\mathbf{2 8 f}-\mathbf{h}$ with $\mathbf{7}$ furnished amines 16f-h which was followed by methylation to afford $\mathbf{6 f}-\mathbf{h}$ as orange solids with $\geq 98 \%$ trans-isomer.
The synthetic strategies for the synthesis of compound $\mathbf{6 i}$ were reported in our previous communication [7].

In the subseries depicted in Table 3, several notable differences in both the UV-vis spectra (Figure S1, Supporting Information File 1) and the photoisomerization are observed. When the substituent $\mathrm{Y}$ is a halogen atom, we observe a slight bathochromic shift of the $\pi-\pi^{*}$ band to higher wavelengths with increasing size of the heteroatom, from $323 \mathrm{~nm}$ for $\mathrm{Y}=\mathrm{H}(\mathbf{3 e})$ to $339 \mathrm{~nm}$ for $\mathrm{Y}=\mathrm{I}$ (6e) (Table 3, Figure 4A). When the group $\mathrm{Y}$ is $\mathrm{OMe}$ (6f), this shift is larger due to the higher EDG properties of $\mathrm{MeO}\left(\lambda_{\max }=352 \mathrm{~nm}\right)$ and this is slightly increased with $\mathrm{Y}=\operatorname{OiPr}\left(6 \mathrm{~g}, \lambda_{\max }=355 \mathrm{~nm}\right)$. The shift is highest for $\mathrm{Y}=\mathrm{NMe}_{2}\left(\mathbf{6 i}, \lambda_{\max }=387 \mathrm{~nm}\right)$. When the oxygen atom of $\mathbf{6} \mathbf{f}$ is replaced by a sulfur atom, the bathochromic shift of the $\pi-\pi^{*}$ band is also increased $\left(\mathbf{6 h}, \lambda_{\max }=373 \mathrm{~nm}\right.$, Table 3, Figure 4A). This high capacity of sulfur substituents to induce a bathochromic effect has already been reported in the azobenzene field [33]. The trans-cis photoisomerization for $\mathbf{3 e}, \mathbf{4 d}, \mathbf{6 b}$ and $\mathbf{6 d - h}$ in general gives a high percentage of $c i s$-isomer (89-93\%) with two exceptions. Compound $6 \mathbf{h}$ shows a PSS of only $65 \%$ cis-isomer due to a poor separation of the $\pi-\pi^{*}$ and $\mathrm{n}-\pi^{*}$ bands as a result of the red-shifting by the SMe group (Figure S1A,B, Supporting Information File 1), whereas $6 \mathbf{i}$ decomposes upon irradiation with $360 \mathrm{~nm}$ light (as previously reported by us [7]) leading to its exclusion from further characterization. The $\mathrm{PSS}_{360}$ forms of exemplary compounds $\mathbf{4 d}, \mathbf{6 e}$ 
<smiles>O=Cc1cc(/N=N/c2ccccc2Br)ccc1F</smiles>

28b (a)<smiles>CC(C)(C)N</smiles><smiles>[X]c1ccc(/N=N/c2ccccc2Br)cc1C=O</smiles>

(d)<smiles>CNCC1CC2CC1C(C)(C)C2CNC</smiles>

(e)<smiles>[Y]c1ccc(N=Nc2ccccc2Br)cc1CN(C)CC1=CC2CC1C(C)(C)C2</smiles>

(f)<smiles>[Y]c1ccc(N=Nc2ccccc2Br)cc1C[N+](C)(C)CC1=CC2CCC1(C)C2</smiles>

6f-h

Scheme 4: Synthetic strategies for compounds 6f-h (Y = OMe, OiPr, SMe). Reagents and conditions: (a) $\mathrm{NaOMe}$ or $\mathrm{NaSMe}$ (1.0-1.2 equiv), MeOH or DMF, $65{ }^{\circ} \mathrm{C}, 30-60 \mathrm{~min}, 88-90 \%$. (b) PhMe, $110{ }^{\circ} \mathrm{C}$, Dean-Stark, $20 \mathrm{~h}, 99 \%$; (c) NaH $\left(1.0\right.$ equiv), DMSO, $100{ }^{\circ} \mathrm{C}, 1 \mathrm{~h} ;(\mathrm{d}) \mathrm{THF} / \mathrm{H}_{2} \mathrm{O} / \mathrm{AcOH}$ $50: 15: 1$, rt, 16 h, 79\% (two steps); (e) i) $\mathrm{Et}_{3} \mathrm{~N}$ (1.3-1.4 equiv), DCM, rt, 10-30 min; ii) $\mathrm{NaBH}(\mathrm{OAc})_{3}$ (1.6 equiv), rt, 6-16 h, 84-95\%; (f) Mel (20 equiv), DCM, rt, 20 h, 86-90\%.

and $\mathbf{6}$ have thermal half-lives of 55 [7], 28 and 29 [7] days, respectively, at $10 \mu \mathrm{M}$ in HEPES (4-(2-hydroxyethyl)-1-piperazineethanesulfonic acid) buffer with $1 \%$ DMSO at $25{ }^{\circ} \mathrm{C}$ and we consider this to be in line with the expectations (vide supra).
The binding affinity of trans-3e, $\mathbf{4 d}, \mathbf{6 b}$ and $\mathbf{6 d}-\mathbf{h}$ (Table 3 ) is in the low micromolar range with a low PAS value upon illumination. Initial pilot studies on $\left[{ }^{35} \mathrm{~S}\right]-\mathrm{GTP} \gamma \mathrm{S}$ binding after CXCR3 stimulation with single concentrations of subseries 6

Table 3: Structure and results of photochemical and binding characterization of compounds $\mathbf{3 e}, \mathbf{4 d}, \mathbf{6 b}$ and $\mathbf{6 d - i}$.<smiles>[Y]c1ccc(N=Nc2ccccc2Br)cc1CN(C)CC1C=CC2(C)CC1C2</smiles>

$3 e, 4 d, 6 b, 6 d-i$

\begin{tabular}{|c|c|c|c|c|c|c|c|c|c|c|}
\hline \multirow[b]{2}{*}{ Compound } & \multirow[b]{2}{*}{$Y$} & \multicolumn{3}{|c|}{ Photochemistry } & \multirow[b]{2}{*}{ SEM } & \multicolumn{5}{|c|}{ CXCR3 binding affinity } \\
\hline & & $\lambda_{\max } \operatorname{trans}$ & $\begin{array}{c}\lambda_{\max } c i s \\
n-\pi^{* a}\end{array}$ & $\begin{array}{c}\mathrm{PSS}_{360} \\
(\% \text { area cis })^{\mathrm{b}}\end{array}$ & & $\underset{\operatorname{trans}^{\mathrm{c}}}{\mathrm{p} K_{\mathrm{i}}}$ & SEM & $\begin{array}{c}\mathrm{pK}_{\mathrm{i}} \\
\mathrm{PSS}_{360^{\mathrm{c}}}\end{array}$ & SEM & PAS $^{d}$ \\
\hline $3 e^{e}$ & $\mathrm{H}$ & 323 & 421 & 88.9 & 0.4 & 6.3 & 0.0 & 5.7 & 0.1 & 4.0 \\
\hline $6 b^{e}$ & $\mathrm{~F}$ & 325 & 417 & 92.7 & 0.1 & 6.0 & 0.0 & 5.4 & 0.0 & 4.0 \\
\hline
\end{tabular}


Table 3: Structure and results of photochemical and binding characterization of compounds $3 \mathbf{e}, \mathbf{4 d}, \mathbf{6 b}$ and $6 \mathbf{d}-\mathbf{i}$. (continued)

\begin{tabular}{|c|c|c|c|c|c|c|c|c|c|c|}
\hline $4 d^{e}$ & $\mathrm{Cl}$ & 328 & 422 & 92.6 & 0.2 & 5.9 & 0.0 & 5.6 & 0.0 & 2.0 \\
\hline $6 d^{e}$ & $\mathrm{Br}$ & 333 & 420 & 92.6 & 0.2 & 5.8 & 0.0 & 5.4 & 0.0 & 2.5 \\
\hline $6 e$ & I & 339 & 424 & 90.5 & 1.0 & 5.5 & 0.1 & 5.5 & 0.0 & 1.0 \\
\hline $6 f^{e}$ & OMe & 352 & 424 & 92.1 & 0.1 & 5.4 & 0.0 & 5.0 & 0.0 & 2.5 \\
\hline $6 g$ & OiPr & 355 & 424 & 89.0 & 0.4 & 5.1 & 0.2 & 5.0 & 0.0 & 1.3 \\
\hline $6 h$ & SMe & 373 & $\approx 425^{f}$ & 64.5 & 1.7 & 5.3 & 0.0 & 5.5 & 0.1 & 0.6 \\
\hline $6 \mathbf{i}^{\mathrm{e}}$ & $\mathrm{NMe}_{2}$ & 387 & dec..$^{g}$ & dec..$^{g}$ & & & & & & \\
\hline
\end{tabular}

aThe absorbance maxima were extracted from UV-vis spectra at $25 \mu \mathrm{M}$ in PBS buffer with $1 \%$ DMSO. b\% of cis-isomer at the photostationary state (PSS 360 ) in $68 \%$ TRIS buffer and $32 \%$ DMSO (1 mM) measured after being pre-irradiated at $360 \mathrm{~nm}$ as obtained by LC-MS integration of the cis and trans-isomer signals at $265 \mathrm{~nm}$. The mean and SEM of at least two experiments are shown. 'Binding affinity of trans-isomer or PSS 360 as measured

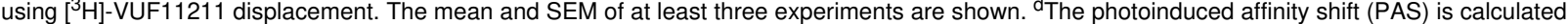
as the ratio of the $K_{\mathrm{i}} \mathrm{PSS}_{360}$ and $K_{\mathrm{i}}$ trans. ${ }^{\mathrm{e}} \mathrm{Compound}$ was previously described by us [7]. ${ }^{\mathrm{f}}$ Could not be determined accurately due to partial overlapping of the $\Pi-\Pi^{*}$ and $n-\Pi^{*}$ bands. ${ }^{9}$ Compound decomposes under illumination.

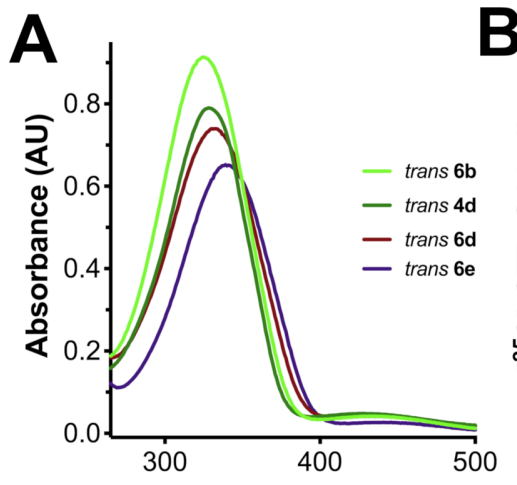

Wavelength $(\mathrm{nm})$

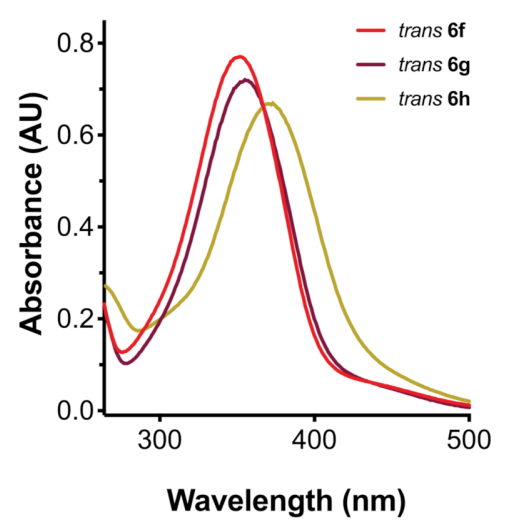

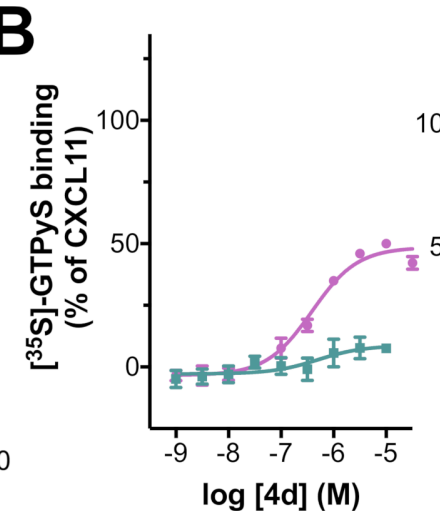

$\log [4 d](M)$

C

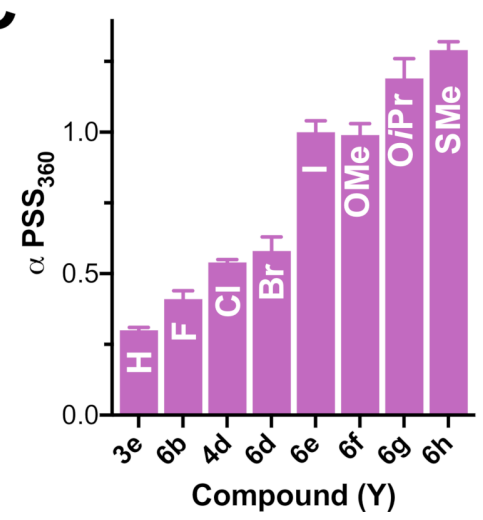

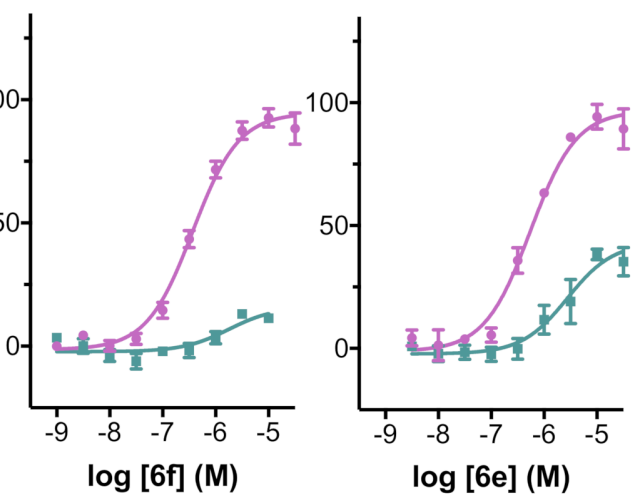

D

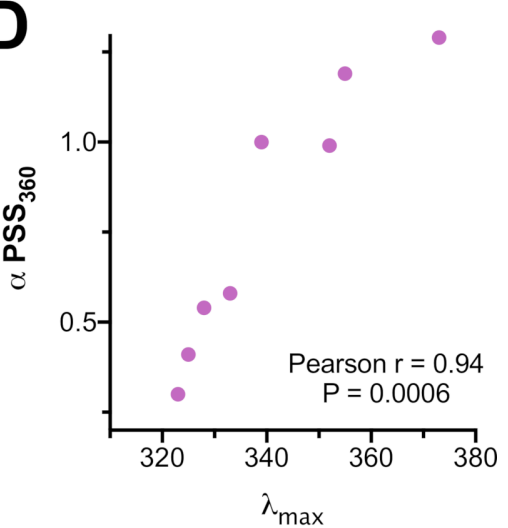

Figure 4: Properties of subseries $3 \mathbf{e}, \mathbf{4 d}, \mathbf{6 b}$ and $\mathbf{6 d - h}$. (A) UV-vis absorption spectra of (top) trans-isomers of $\mathbf{6 b}, \mathbf{4 d}, \mathbf{6 d}$ and $\mathbf{6 e}$ (having substituent $\mathrm{Y}=\mathrm{F}, \mathrm{Cl}, \mathrm{Br}$ and I, respectively) and (bottom) $\mathbf{6 f}, \mathbf{6 g}$ and $\mathbf{6 h}$ (having $\mathrm{Y}=\mathrm{OMe}$, OiPr and SMe, respectively). (B) Functional dose-response curves using $\left[{ }^{35}\right.$ S]-GTPYS assay exemplified for $\mathbf{4 d}, \mathbf{6 f}$ and $\mathbf{6 e}$, respectively. (C) Summary of the efficacies of compounds $3 \mathbf{e}, \mathbf{4 d}, \mathbf{6 b}$ and $\mathbf{6 d}-\mathbf{h}$ at PSS 360 . (D) Correlation between the bathochromic shifting of the $\Pi-\Pi^{*}$ band and the intrinsic activity of PSS 360 for the compounds in Table 4 .

(data not shown) showed substantial levels of CXCR3 agonism in this group of compounds. For subseries $\mathbf{6}$ (and associated $\mathbf{3 e}$ and 4d) we therefore generated dose-response curves for the trans and $\mathrm{PSS}_{360}$ forms (Figure S4, Supporting Information File 1) using the same $\left[{ }^{35} \mathrm{~S}\right]-\mathrm{GTP} \gamma \mathrm{S}$ functional assay and calcu- lated the intrinsic activity $(\alpha)$ and potency $\left(\mathrm{EC}_{50}\right)$. As reported in our previous communication for some of these compounds [7], the $\mathrm{PSS}_{360}$ forms give agonism with high nanomolar potencies while most trans compounds are antagonists or partial agonists with very low efficacies (Table 4). However, when the 
Table 4: Structure and results of functional characterization of compounds $3 \mathbf{e}, \mathbf{4 d}, \mathbf{6 b}$ and $6 \mathbf{d}-\mathbf{h}$.

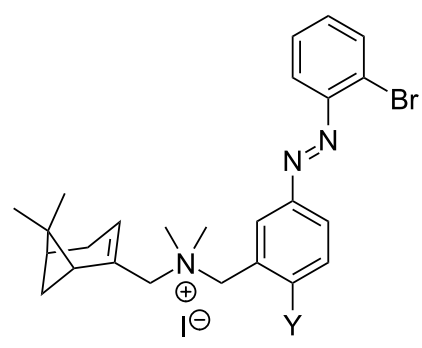

$3 e, 4 d, 6 b, 6 d-h$

\begin{tabular}{|c|c|c|c|c|c|c|c|c|c|c|}
\hline Compound & $\mathrm{Y}$ & $\begin{array}{l}\mathrm{pEC}_{50} \\
\text { trans }^{\mathrm{a}}\end{array}$ & SEM & $\begin{array}{l}\mathrm{pEC}_{50} \\
\mathrm{PSS}_{360} \mathrm{~b}\end{array}$ & SEM & $\alpha$ trans $^{c}$ & SEM & $\alpha \mathrm{PSS}_{360} \mathrm{~d}^{\mathrm{d}}$ & SEM & PDE \\
\hline 1d & - & 6.9 & 0.0 & 6.9 & 0.0 & 1.04 & 0.08 & 1.03 & 0.07 & -0.01 \\
\hline $3 e^{f}$ & $\mathrm{H}$ & n.m.g & n.m.g & 6.5 & 0.1 & 0.05 & 0.03 & 0.30 & 0.01 & 0.25 \\
\hline $6 b^{f}$ & $\mathrm{~F}$ & n.m.g & n.m.g & 6.2 & 0.1 & 0.12 & 0.00 & 0.41 & 0.03 & 0.29 \\
\hline $4 d^{f}$ & $\mathrm{Cl}$ & n.m.g & n.m.g & 6.3 & 0.1 & 0.11 & 0.01 & 0.54 & 0.01 & 0.43 \\
\hline $6 \mathbf{d}^{f}$ & $\mathrm{Br}$ & n.m.g & n.m.g & 6.2 & 0.1 & 0.14 & 0.02 & 0.58 & 0.05 & 0.44 \\
\hline $6 e$ & I & 5.5 & 0.3 & 6.3 & 0.2 & 0.49 & 0.04 & 1.00 & 0.04 & 0.51 \\
\hline $6 f^{f}$ & OMe & n.m.g & n.m.g & 6.4 & 0.1 & 0.16 & 0.01 & 0.99 & 0.04 & 0.83 \\
\hline $6 \mathrm{~g}$ & OiPr & n.m. ${ }^{h}$ & n.m. ${ }^{h}$ & 6.0 & 0.0 & n.m. ${ }^{h}$ & n.m. ${ }^{h}$ & 1.19 & 0.07 & n.m.h \\
\hline $6 h$ & $\mathrm{SMe}$ & 5.7 & 0.3 & 6.1 & 0.1 & 0.85 & 0.08 & 1.29 & 0.03 & 0.44 \\
\hline
\end{tabular}

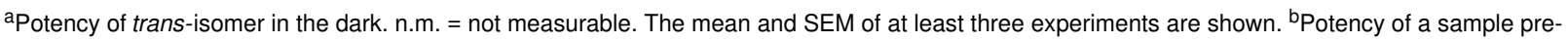
irradiated at $360 \mathrm{~nm}$ to reach the photostationary state. The mean and SEM of at least three experiments are shown. 'Intrinsic activity of trans-isomer in the dark (CXCL11 efficacy set at $\alpha=1)$. The mean and SEM of at least three experiments are shown. Intrinsic activity of a sample pre-irradiated at $360 \mathrm{~nm}$ to reach the photostationary state (CXCL11 efficacy set at $\alpha=1)$. The mean and SEM of at least three experiments are shown. ${ }^{\mathrm{e}}$ The photoinduced difference of efficacy (PDE) is obtained by subtracting $\alpha$ trans from $\alpha \mathrm{PSS}_{360} .{ }^{\mathrm{f}}$ Compound was previously described by us [7]. ${ }^{\mathrm{g} T o o}$ low

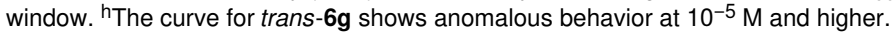

size and/or EDG properties of Y increase, remarkably partial agonism with substantial efficacies appears even for the transisomers, such as for $\mathbf{6 e}, \mathbf{6 g}$ and $\mathbf{6 h}$. The compounds illuminated to $\mathrm{PSS}_{360}$ follow a similar qualitative trend: when the Y substituent is $\mathrm{H}$ or $\mathrm{F}$ (3e and $\mathbf{6 b}$ ), the cis-isomer behaves as a partial agonist with medium efficacy ( $\alpha=0.30-0.41$ ), but when the $\mathrm{Y}$ substituent increases in size and/or EDG properties, the efficacy increases to full efficacy with compounds $\mathbf{6 e - h}(\mathrm{Y}=\mathrm{I}$, $\mathrm{OMe}, \mathrm{OiPr}$ and $\mathrm{SMe}$ ). The trans-form of $\mathbf{6 g}$ shows anomalous behavior at $10^{-5} \mathrm{M}$ and higher (Figure S4, Supporting Information File 1), preventing the extraction of accurate functional values. The PDE value, which reflects efficacies of both the trans and PSS form, appears to have an optimum for $\mathbf{6 f}$ (Figure 4B). Figure 4B also shows more subtle behavior for compounds $4 \mathbf{d}$ and $\mathbf{6 e}$, which harbor a $\mathrm{PDE}$ value of 0.43 and 0.51 , respectively, but in different parts of the efficacy window.

The results reveal that the electron density of the aryl rings, especially of the inner one, plays a key role in inducing agonism in CXCR3. In general, the cis-isomers of the series 2-6 are better CXCR3 agonists. Indeed, the cis-isomers are gen- erally assumed to have an intrinsically higher electron density due to the disruption of the conjugation between the two rings of the azobenzene through the $\mathrm{N}=\mathrm{N}$ bond. Moreover, the electronic properties of the inner substituent $\mathrm{Y}$ have been proven to be of strategic use in increasing the intrinsic activity $(\alpha)$ of the cis-isomers (Figure 4C). This capacity of the Y substituent to alter the electron density is conceivably also related to its capacity to induce a bathochromic shift of the $\pi-\pi^{*}$ band of the trans-isomer. Potential evidence for this can be extracted from the significant correlation between the bathochromic shift and intrinsic activity of $\mathrm{PSS}_{360}$ (Figure 4D) for the subseries $\mathbf{3 e}, \mathbf{4 d}$, 6b and $\mathbf{6 d - h}$, which only differ in the nature of $\mathrm{Y}$ group (Figure 4C, Table 4).

\section{Conclusion}

We report a toolbox of 31 photochromic small-molecule CXCR3 receptor ligands based on the modeling-assisted azologization of a biaryl series reported previously by us [24]. All compounds show affinity for CXCR3 from the high nanomolar to the low micromolar range. Our efforts, however, were focused on exploring the landscape in functional efficacy. To this end, the scaffold was subjected to positional and substitu- 
tion changes in structure, necessitating extensive synthetic efforts through multiple routes. The presence of halogen substituents on the ortho-position of the outer ring (substituent $\mathrm{X}$ ) provides partial agonism for the $c i s$-isomer with a $\mathrm{Br}$ atom being the major exponent, while trans-isomers preserve antagonist behavior. The presence of a substituent on the para-position of the central ring (substituent $\mathrm{Y}$ ) capable of delocalizing $\pi$-electrons increases the efficacy of the cis-isomer. The $c i s$ isomers of compounds with $\mathrm{Y}=\mathrm{I}$, OMe, OiPr or SMe are all full agonists of CXCR3, however, the corresponding transisomers also activate the receptor to varying degrees. In all, our efforts deliver a spectrum of (subtle) efficacy differences. Notable tool compounds are VUF15888 (4d) switching from antagonism to partial agonism $(\mathrm{PDE}=0.43), \operatorname{VUF} 16620(\mathbf{6 e})$ switching from partial agonism to full agonism $(\mathrm{PDE}=0.51)$, and VUF16216 (6f), which represents the optimum balance and provides a CXCR3 photoswitch with a PDE value of 0.83 , i.e., from antagonism to full agonism. Based on the pharmacological properties of these three compounds and the long half-lives of their PSS states, they will be valuable tools for future photopharmacological studies on the dynamic signaling of the chemokine receptor CXCR3.

\section{Supporting Information}

\author{
Supporting Information File 1 \\ Experimental part. \\ [https://www.beilstein-journals.org/bjoc/content/ \\ supplementary/1860-5397-15-244-S1.pdf]
}

\section{Acknowledgements}

All authors acknowledge the Netherlands Organization for Scientific Research for financial support (TOPPUNT, "7 ways to 7TMR modulation (7-to-7)", 718.014.002). We thank Danny Scholten, Chris de Graaf, and Luc Roumen for helpful discussions, Hans Custers for recording HRMS spectra and Mounir Andaloussi for providing key building block 7 .

\section{ORCID ${ }^{\circledR}$ iDs}

Xavier Gómez-Santacana - https://orcid.org/0000-0001-8830-0494 Tamara A. M. Mocking - https://orcid.org/0000-0001-6490-4429 Niels J. Hauwert - https://orcid.org/0000-0002-1217-1670 Prashanna Vijayachandran - https://orcid.org/0000-0002-1047-538X Henry F. Vischer - https://orcid.org/0000-0002-0184-6337 Maikel Wijtmans - https://orcid.org/0000-0001-8955-8016 Rob Leurs - https://orcid.org/0000-0003-1354-2848

\section{Preprint}

A non-peer-reviewed version of this article has been previously published as a preprint doi:10.3762/bxiv.2019.69.v1

\section{References}

1. Hüll, K.; Morstein, J.; Trauner, D. Chem. Rev. 2018, 118, 10710-10747. doi:10.1021/acs.chemrev.8b00037

2. Hoorens, M. W. H.; Szymanski, W. Trends Biochem. Sci. 2018, 43, 567-575. doi:10.1016/j.tibs.2018.05.004

3. Hauwert, N. J.; Mocking, T. A. M.; Da Costa Pereira, D.; Kooistra, A. J.; Wijnen, L. M.; Vreeker, G. C. M.; Verweij, E. W. E.; De Boer, A. H.; Smit, M. J.; De Graaf, C.; Vischer, H. F.; de Esch, I. J. P.; Wijtmans, M.; Leurs, R. J. Am. Chem. Soc. 2018, 140, 4232-4243. doi:10.1021/jacs.7b11422

4. Donthamsetti, P. C.; Winter, N.; Schönberger, M.; Levitz, J.; Stanley, C.; Javitch, J. A.; Isacoff, E. Y.; Trauner, D. J. Am. Chem. Soc. 2017, 139, 18522-18535. doi:10.1021/jacs.7b07659

5. Lachmann, D.; Konieczny, A.; Keller, M.; König, B. Org. Biomol. Chem. 2019, 17, 2467-2478. doi:10.1039/c8ob03221a

6. Westphal, M. V.; Schafroth, M. A.; Sarott, R. C.; Imhof, M. A.; Bold, C. P.; Leippe, P.; Dhopeshwarkar, A.; Grandner, J. M.; Katritch, V.; Mackie, K.; Trauner, D.; Carreira, E. M.; Frank, J. A. J. Am. Chem. Soc. 2017, 139, 18206-18212. doi:10.1021/jacs.7b06456

7. Gómez-Santacana, X.; de Munnik, S. M.; Vijayachandran, P.; Da Costa Pereira, D.; Bebelman, J. P. M.; de Esch, I. J. P.; Vischer, H. F.; Wijtmans, M.; Leurs, R. Angew. Chem., Int. Ed. 2018, 57, 11608-11612. doi:10.1002/anie.201804875

8. Morstein, J.; Awale, M.; Reymond, J.-L.; Trauner, D. ACS Cent. Sci. 2019, 5, 607-618. doi:10.1021/acscentsci.8b00881

9. Hartley, G. S. Nature 1937, 140, 281. doi:10.1038/140281a0

10. Ricart-Ortega, M.; Font, J.; Llebaria, A. Mol. Cell. Endocrinol. 2019, 488, 36-51. doi:10.1016/j.mce.2019.03.003

11. Hauwert, N. J.; Mocking, T. A. M.; Da Costa Pereira, D.; Lion, K.; Huppelschoten, Y.; Vischer, H. F.; De Esch, I. J. P.; Wijtmans, M.; Leurs, R. Angew. Chem., Int. Ed. 2019, 58, 4531-4535. doi:10.1002/anie.201813110

12. Hauser, A. S.; Attwood, M. M.; Rask-Andersen, M.; Schiöth, H. B.; Gloriam, D. E. Nat. Rev. Drug Discovery 2017, 16, 829-842. doi:10.1038/nrd.2017.178

13. Schönberger, M.; Trauner, D. Angew. Chem., Int. Ed. 2014, 53, 3264-3267. doi:10.1002/anie.201309633

14. Pittolo, S.; Gómez-Santacana, X.; Eckelt, K.; Rovira, X.; Dalton, J.; Goudet, C.; Pin, J.-P.; Llobet, A.; Giraldo, J.; Llebaria, A.; Gorostiza, P. Nat. Chem. Biol. 2014, 10, 813-815. doi:10.1038/nchembio.1612

15. Bahamonde, M. I.; Taura, J.; Paoletta, S.; Gakh, A. A.; Chakraborty, S.; Hernando, J.; Fernández-Dueñas, V.; Jacobson, K. A.; Gorostiza, P.; Ciruela, F. Bioconjugate Chem. 2014, 25, 1847-1854. doi:10.1021/bc5003373

16. Levitz, J.; Pantoja, C.; Gaub, B.; Janovjak, H.; Reiner, A.; Hoagland, A.; Schoppik, D.; Kane, B.; Stawski, P.; Schier, A. F.; Trauner, D.; Isacoff, E. Y. Nat. Neurosci. 2013, 16, 507-516. doi:10.1038/nn.3346

17. Rovira, X.; Trapero, A.; Pittolo, S.; Zussy, C.; Faucherre, A.; Jopling, C.; Giraldo, J.; Pin, J.-P.; Gorostiza, P.; Goudet, C.; Llebaria, A. Cell Chem. Biol. 2016, 23, 929-934. doi:10.1016/j.chembiol.2016.06.013

18. Zussy, C.; Gómez-Santacana, X.; Rovira, X.; De Bundel, D.; Ferrazzo, S.; Bosch, D.; Asede, D.; Malhaire, F.; Acher, F.; Giraldo, J.; Valjent, E.; Ehrlich, I.; Ferraguti, F.; Pin, J.-P.; Llebaria, A.; Goudet, C. Mol. Psychiatry 2018, 23, 509-520. doi:10.1038/mp.2016.223 
19. Agnetta, L.; Bermudez, M.; Riefolo, F.; Matera, C.; Claro, E.; Messerer, R.; Littmann, T.; Wolber, G.; Holzgrabe, U.; Decker, M. J. Med. Chem. 2019, 62, 3009-3020. doi:10.1021/acs.jmedchem.8b01822

20. Rustler, K.; Maleeva, G.; Bregestovski, P.; König, B. Beilstein J. Org. Chem. 2019, 15, 780-788. doi:10.3762/bjoc.15.74

21. Broichhagen, J.; Podewin, T.; Meyer-Berg, H.; von Ohlen, Y.; Johnston, N. R.; Jones, B. J.; Bloom, S. R.; Rutter, G. A.; Hoffmann-Röder, A.; Hodson, D. J.; Trauner, D. Angew. Chem., Int. Ed. 2015, 54, 15565-15569. doi:10.1002/anie.201506384

22. Broichhagen, J.; Johnston, N. R.; von Ohlen, Y.; Meyer-Berg, H.; Jones, B. J.; Bloom, S. R.; Rutter, G. A.; Trauner, D.; Hodson, D. J. Angew. Chem., Int. Ed. 2016, 55, 5865-5868. doi:10.1002/anie.201600957

23. Gómez-Santacana, X.; Pittolo, S.; Rovira, X.; Lopez, M.; Zussy, C.; Dalton, J. A. R.; Faucherre, A.; Jopling, C.; Pin, J.-P.; Ciruela, F.; Goudet, C.; Giraldo, J.; Gorostiza, P.; Llebaria, A. ACS Cent. Sci. 2017, 3, 81-91. doi:10.1021/acscentsci.6b00353

24. Wijtmans, M.; Scholten, D. J.; Roumen, L.; Canals, M.; Custers, H.; Glas, M.; Vreeker, M. C. A.; de Kanter, F. J. J.; de Graaf, C.; Smit, M. J.; de Esch, I. J. P.; Leurs, R. J. Med. Chem. 2012, 55, 10572-10583. doi:10.1021/jm301240t

25. Wijtmans, M.; Scholten, D.; Mooij, W.; Smit, M. J.; de Esch, I. J. P.; de Graaf, C.; Leurs, R. Exploring the CXCR3 Chemokine Receptor with Small-Molecule Antagonists and Agonists. In Chemokines: Chemokines and Their Receptors in Drug Discovery; Tschammer, N., Ed.; Topics in Medicinal Chemistry; Springer International Publishing: Cham, Switzerland, 2015; pp 119-185. doi:10.1007/7355_2014_75

26. MOE, Version 2016.0802; Chemical Computing Group, Inc.: Chemical Computing Group, Inc, 2016.

27. Fliegl, H.; Köhn, A.; Hättig, C.; Ahlrichs, R. J. Am. Chem. Soc. 2003, 125, 9821-9827. doi:10.1021/ja034433o

28. Wijtmans, M.; Verzijl, D.; Bergmans, S.; Lai, M.; Bosch, L.; Smit, M. J.; de Esch, I. J. P.; Leurs, R. Bioorg. Med. Chem. 2011, 19, 3384-3393. doi:10.1016/j.bmc.2011.04.035

29. García-Amorós, J.; Velasco, D. Beilstein J. Org. Chem. 2012, 8, 1003-1017. doi:10.3762/bjoc.8.113

30. Bandara, H. M. D.; Burdette, S. C. Chem. Soc. Rev. 2012, 41, 1809-1825. doi:10.1039/c1cs15179g

31. Scholten, D. J.; Wijtmans, M.; van Senten, J. R.; Custers, H.; Stunnenberg, A.; de Esch, I. J. P.; Smit, M. J.; Leurs, R. Mol. Pharmacol. 2015, 87, 639-648. doi:10.1124/mol.114.095265

32. Engle, K. M.; Luo, S.-X.; Grubbs, R. H. J. Org. Chem. 2015, 80, 4213-4220. doi:10.1021/acs.joc.5b00563

33. Nishioka, H.; Liang, X.; Kato, T.; Asanuma, H. Angew. Chem., Int. Ed. 2012, 51, 1165-1168. doi:10.1002/anie.201106093

\section{License and Terms}

This is an Open Access article under the terms of the Creative Commons Attribution License (http://creativecommons.org/licenses/by/4.0). Please note that the reuse, redistribution and reproduction in particular requires that the authors and source are credited.

The license is subject to the Beilstein Journal of Organic Chemistry terms and conditions: (https://www.beilstein-journals.org/bjoc)

The definitive version of this article is the electronic one which can be found at: doi:10.3762/bjoc. 15.244 